\title{
The glacial isostatic adjustment signal at present day in northern Europe and the British Isles estimated from geodetic observations and geophysical models
}

\author{
Karen M. Simon ${ }^{1}$, Riccardo E. M. Riva ${ }^{1}$, Marcel Kleinherenbrink ${ }^{1}$, and Thomas Frederikse ${ }^{1,2}$ \\ ${ }^{1}$ Delft University of Technology, Department of Geoscience and Remote Sensing, Stevinweg 1, \\ 2628 CN Delft, the Netherlands \\ ${ }^{2}$ Utrecht University, Institute for Marine and Atmospheric Research, Princetonplein 5, 3584 CC Utrecht, the Netherlands
}

Correspondence: Karen M. Simon (k.m.simon@tudelft.nl)

Received: 29 January 2018 - Discussion started: 7 February 2018

Revised: 6 May 2018 - Accepted: 13 May 2018 - Published: 15 June 2018

\begin{abstract}
The glacial isostatic adjustment (GIA) signal at present day is constrained via the joint inversion of geodetic observations and GIA models for a region encompassing northern Europe, the British Isles, and the Barents Sea. The constraining data are Global Positioning System (GPS) vertical crustal velocities and GRACE (Gravity Recovery and Climate Experiment) gravity data. When the data are inverted with a set of GIA models, the best-fit model for the vertical motion signal has a $\chi^{2}$ value of approximately 1 and a maximum a posteriori uncertainty of $0.3-0.4 \mathrm{~mm} \mathrm{yr}^{-1}$. An elastic correction is applied to the vertical land motion rates that accounts for present-day changes to terrestrial hydrology as well as recent mass changes of ice sheets and glaciered regions. Throughout the study area, mass losses from Greenland dominate the elastic vertical signal and combine to give an elastic correction of up to $+0.5 \mathrm{~mm} \mathrm{yr}^{-1}$ in central Scandinavia. Neglecting to use an elastic correction may thus introduce a small but persistent bias in model predictions of GIA vertical motion even in central Scandinavia where vertical motion is dominated by GIA due to past glaciations. The predicted gravity signal is generally less well-constrained than the vertical signal, in part due to uncertainties associated with the correction for contemporary ice mass loss in Svalbard and the Russian Arctic. The GRACE-derived gravity trend is corrected for present-day ice mass loss using estimates derived from the ICESat and CryoSat missions, although a difference in magnitude between GRACE-inferred and altimetryinferred regional mass loss rates suggests the possibility of a non-negligible GIA response here either from millennialscale or Little Ice Age GIA.
\end{abstract}

\section{Introduction}

Glacial isostatic adjustment (GIA) is the process by which the Earth's crust and underlying mantle deform in response to surface loading and unloading by large ice sheets and glaciers (e.g. Peltier and Andrews, 1976; Wu and Peltier, 1982). Glacial isostatic deformation at present day can include contributions from both recent (annual, decadal) variations in ice cover as well as contributions from millennial-scale variations in ice cover during Pleistocene and Holocene glaciation cycles, although in this study GIA refers to the latter paleo-signal, specifically from the last glaciation. Ongoing GIA is usually the dominant present-day deformation signal in formerly glaciated areas (for example, up to approximately $1 \mathrm{~cm} \mathrm{yr}^{-1}$ land uplift around the northwestern Gulf of Bothnia; Lidberg et al., 2010; Kierulf et al., 2014). Outside formerly glaciated regions, the GIA signal from past glaciations often remains large enough to form a significant component of observed present-day deformation and sea-level change rates. A constraint on the GIA signal at present day is therefore required for accurate separation of the longer timescale and the more recent contributions to present-day land deformation and gravity change (Peltier, 1998; Tamisiea, 2011). This problem is complicated further by the fact that the GIA signal itself is temporally and spatially complex, therefore making it challenging for models to constrain some of the fundamental parameters relating to both ice cover during past glaciations and the structure of the Earth.

In Scandinavia, the GIA process has been studied extensively and constrained with data including relative sea-level 
indicators, Global Positioning System (GPS) measurements and satellite gravity data (e.g. Lambeck et al., 1998; Milne et al., 2001; Steffen et al., 2010; see also Steffen and Wu, 2011, for a review). While the GIA process in the region of the former Fennoscandian Ice Sheet is probably more extensively studied than anywhere else in the world, GIA in the Barents Sea is by comparison less well understood due in part to the lack of observational evidence left behind by a marinebased ice sheet. Auriac et al. (2016) provide a recent summary of GIA models in the Barents Sea region. Studies have also focussed on the smaller British Isles region, which experiences GIA deformation in response to deglaciation of both the local British Isles Ice Sheet and the larger adjacent Fennoscandian Ice Sheet (Bradley et al., 2011; Kuchar et al., 2012). The ice sheet evolution of the region as a whole was recently summarized by Patton et al. (2017). These studies and many others have provided valuable insight into regional GIA processes. The majority of GIA models are, however, forward models which can be limited by uncertainties in both the ice sheet model and Earth model. Furthermore, because a best-fit forward GIA model is generally a single Earth-ice model combination, their predictions of GIA deformations are typically provided without uncertainties.

This paper constrains the GIA signal in northern Europe through the simultaneous inversion of vertical land motion rates from GPS and gravity change rates from GRACE (Gravity Recovery and Climate Experiment). The semiempirical method also estimates corresponding uncertainties for the preferred model(s), which, relative to forward model studies, is a notable advantage of semi-empirical or data-driven methodologies. Similar empirical and semiempirical approaches have been implemented to estimate regional long-term GIA signals in Antarctica (Riva et al., 2009; Gunter et al., 2014), North America (Sasgen et al., 2012; Simon et al., 2017), Alaska (Jin et al., 2016), and Fennoscandia (Hill et al., 2010; Müller et al., 2012; Zhao et al., 2012). Here, our methodology is based on that of Hill et al. (2010); relative to their previous work, we update both the GPS and GRACE datasets, incorporate a second model ice sheet history into the a priori input, and expand the study area to include regions south and west of Scandinavia, including the British Isles, as well as the Barents Sea to the north. Rather than focus on model parameter estimation, we focus on the constraint on the GIA signal at present day. There are three main goals: (i) to model the paleo-GIA signal at present day in a continuous region between Scandinavia and the British Isles; (ii) to estimate empirically the uncertainty of the modelled signal; and (iii) to assess the importance of applying an elastic correction to the vertical land motion data.

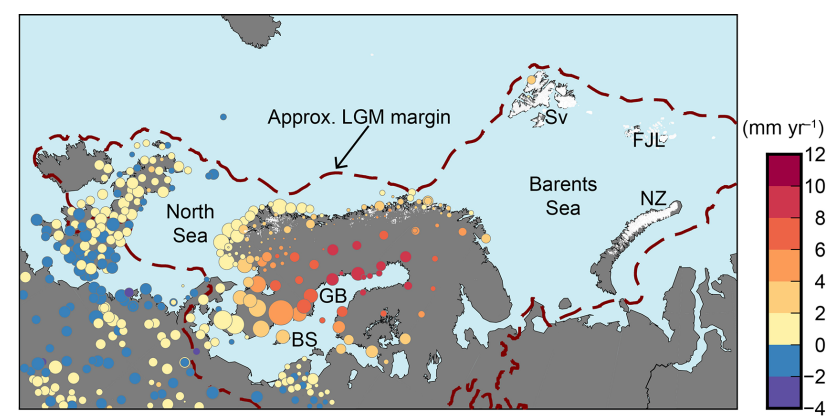

Figure 1. Rates of vertical land motion $\left(\mathrm{mm} \mathrm{yr}^{-1}\right)$ for the GPS data used in the inversion, after correction for elastic effects (Sect. 2.3). BS - Baltic Sea; FJL - Franz Josef Land; GB - Gulf of Bothnia; NZ - Novaya Zemlya; Sv - Svalbard; FJL and NZ - Russian Arctic. Dark red dashed line (Hughes et al., 2016) shows the approximate boundary of ice cover at the Last Glacial Maximum (LGM) (ice cover on Iceland not shown). White shading indicates presentday glaciers. The size of the circles is inversely proportional to the measurement uncertainty.

\section{Model inputs and method}

\subsection{GPS data}

Rates of vertical land motion measured by GPS are taken from both Kierulf et al. (2014) and the Nevada Geodetic Laboratory (Blewitt et al., 2016) (Fig. 1). The Kierulf et al. (2014) dataset has relatively dense coverage within the region of the former load centre of the Fennoscandian Ice Sheet (FIS), particularly in Norway, but sparse coverage elsewhere. The data from Blewitt et al. (2016) are thus used for the region outside the former ice sheet margin. The Kierulf et al. (2014) dataset has 150 stations with time series lengths of at least 3 years. The data from Blewitt et al. (2016) span 1996-2016 and have been limited to sites which have at least 10 years of data. To avoid spatial overlap of sites, the data from Blewitt et al. (2016) have been additionally filtered to include only one site within a $30 \mathrm{~km}$ radius (where the site selected within the radius is the one with the largest number of usable data epochs). The subset of data from Blewitt et al. (2016) has 309 stations. Combined with the Kierulf et al. (2014) data, there are 459 measurements in total.

As further described in Kierulf et al. (2014), their rates were derived using the GAMIT/GLOBK GPS analysis software (Herring et al., 2011) and have uncertainties that assume a combination of white noise and flicker noise, while the data from the Nevada Geodetic Laboratory were calculated using the MIDAS trend estimator, an algorithm that is less sensitive to discontinuities in GPS time series (Blewitt et al., 2016). Although the processing technique differs for each dataset, the two datasets are combined in order to achieve the best possible spatial coverage in the study area. Common sites in the two datasets compare within the observational uncertainties at all but 2 of 31 sites, and no appar- 
ent bias is observed between the differences at the shared sites (Fig. A1). Because the uncertainties are consistently larger for the data from the Nevada Geodetic Laboratory than for the data from Kierulf et al. (2014), we use the common sites to determine an average uncertainty scaling factor $(\sim 2.25)$ to apply to the uncertainties in the latter dataset. The scaling avoids significantly biasing the inversion result towards fitting either dataset. Both datasets are aligned in the International Terrestrial Reference Frame, 2008 (Altamimi et al., 2011), which is consistent with the centre of mass $(\mathrm{CM})$ frame to within $\sim 0.2 \mathrm{~mm} \mathrm{yr}^{-1}$. As described in Sect. 2.3, an elastic correction is applied that accounts for recent changes in ice sheet and glacier volumes and terrestrial hydrology.

\subsection{GRACE}

The GRACE data are processed as in Simon et al. (2017). Rates of gravity change for a 10.5-year period from February 2004 to June 2014 are estimated using 113 GRACE Release-05 (RL05) monthly solutions from the University of Texas at Austin Center for Space Research (CSR). The coefficients are truncated at degree and order 96. Part of the GIA signal may also be lost during the filtering, particularly at higher orders; the typical spatial resolution of the signal is $\sim 300 \mathrm{~km}$ (Siemes et al., 2013). Values estimated from Satellite Laser Ranging (Cheng et al., 2013) replace the $\mathrm{C}_{20}$ coefficients. Following Klees et al. (2008), the monthly fields are filtered with a statistically optimal Wiener filter. The optimal filter incorporates the full variance-covariance information of the monthly solutions and less aggressively filters in regions where signal is stronger. A mass trend is estimated that accounts for bias, annual, and semi-annual variations (Fig. 2). The signal uncertainty is represented by the full variance-covariance matrix of the trend. Corrections for changes in the terrestrial hydrology cycle and ice mass loss from Svalbard and the Russian Arctic are applied as described in Sect. 2.3.

\subsection{Corrections for terrestrial hydrology and present-day ice melt}

Changes in terrestrial hydrology as well as present-day ice mass loss from Greenland and glaciers and ice caps in Svalbard, the Russian Arctic, and Scandinavia may form a significant contribution to the total measured gravity change and vertical motion rates within the study area.

\subsubsection{GRACE}

In the continental region and south of approximately $71.5^{\circ} \mathrm{N}$ latitude, hydrological changes are the sum of dam retention values (Chao et al., 2008) and anthropogenic groundwater depletion is estimated with the model PCR-GLOBWB (Wada et al., 2014). The trend is computed for 2004-2014 from 11 annual means on a $2^{\circ} \times 2^{\circ}$ grid, consistent with the resolution of the GRACE data. In glaciered regions (Scandinavia, Svalbard, and the Russian Arctic), the hydrology model is not used to correct the input rates. Rather, it is assumed that present-day estimates of regional ice melt derived from altimetry observations should more accurately capture the dominant hydrological signals that would be modelled by PCR-GLOBWB. The corrections for mass loss from the glaciers are also filtered to be consistent with the spatial resolution of the GRACE data. The total correction for hydrology and glacial mass loss is shown in Fig. 2c, the individual contributions are shown in Fig. A2.

Estimates of present-day mass changes in Scandinavia, the Russian Arctic, and Svalbard are summarized in Table 1 for various studies, and vary considerably depending on estimation method and time period. Ice mass loss in Scandinavia originates from glaciers in western Norway and is consistently small with estimated rates between -1.2 to $-2 \mathrm{Gtyr}^{-1}$. Here, we apply a mass loss rate of $-1.3 \mathrm{Gt} \mathrm{yr}^{-1}$, determined by glaciological modelling (Marzeion et al., 2012, 2015).

In the Russian Arctic, glaciological estimates of mass change are consistent within uncertainties for the different time periods and suggest mass change between -21.0 and $-24.7 \mathrm{Gtyr}^{-1}$. These rates are approximately twice those estimated by the ICESat and CryoSat missions, which estimate mass changes in this region of between -10.5 and $-14.9 \mathrm{Gt} \mathrm{yr}^{-1}$ (Bert Wouters, personal communication, 2016), with a small acceleration observed after 2010. The smallest net mass change estimate for the Russian Arctic comes from GRACE, with $-5.7 \mathrm{Gtyr}^{-1}$ mass change observed between 2003 and 2013 (Schrama et al., 2014).

In Svalbard, estimated mass change rates are more discrepant. Again, glaciological estimates are the largest, but two estimates of -42.0 and $-17.0 \mathrm{Gtyr}^{-1}$ between 2003 and 2009 are not consistent within uncertainties and differ in magnitude by more than a factor of 2 . Laser and radar altimetry estimates are smaller and suggest a clear acceleration in mass loss since 2010 (-4.6 $\mathrm{Gt} \mathrm{yr}^{-1}$ between 2003 and 2009 and $-16.5 \mathrm{Gtyr}^{-1}$ between 2010 and 2014; Bert Wouters, personal communication, 2016). As with the Russian Arctic, GRACE is the estimation technique that records the smallest net mass change, with $-4.0 \mathrm{Gt} \mathrm{yr}^{-1}$ estimated in Svalbard between 2003 and 2013 (Schrama et al., 2014).

GRACE measures total mass changes (solid Earth plus cryosphere), and thus a correction for one needs to be applied in order to isolate the other. While the glaciological values and the altimetry estimates (which are corrected for crustal uplift due to GIA) are both intended to represent changes to the cryosphere, the differing mass change estimates among measurement techniques for the Russian Arctic and Svalbard raise the question of which value to use when applying a correction to the total GRACE trend shown in Fig. 2a. Relative to GRACE, the glaciological and altimetry methods both consistently infer larger mass losses, suggesting that GRACE contains a significant mass gain signal from the solid Earth, 

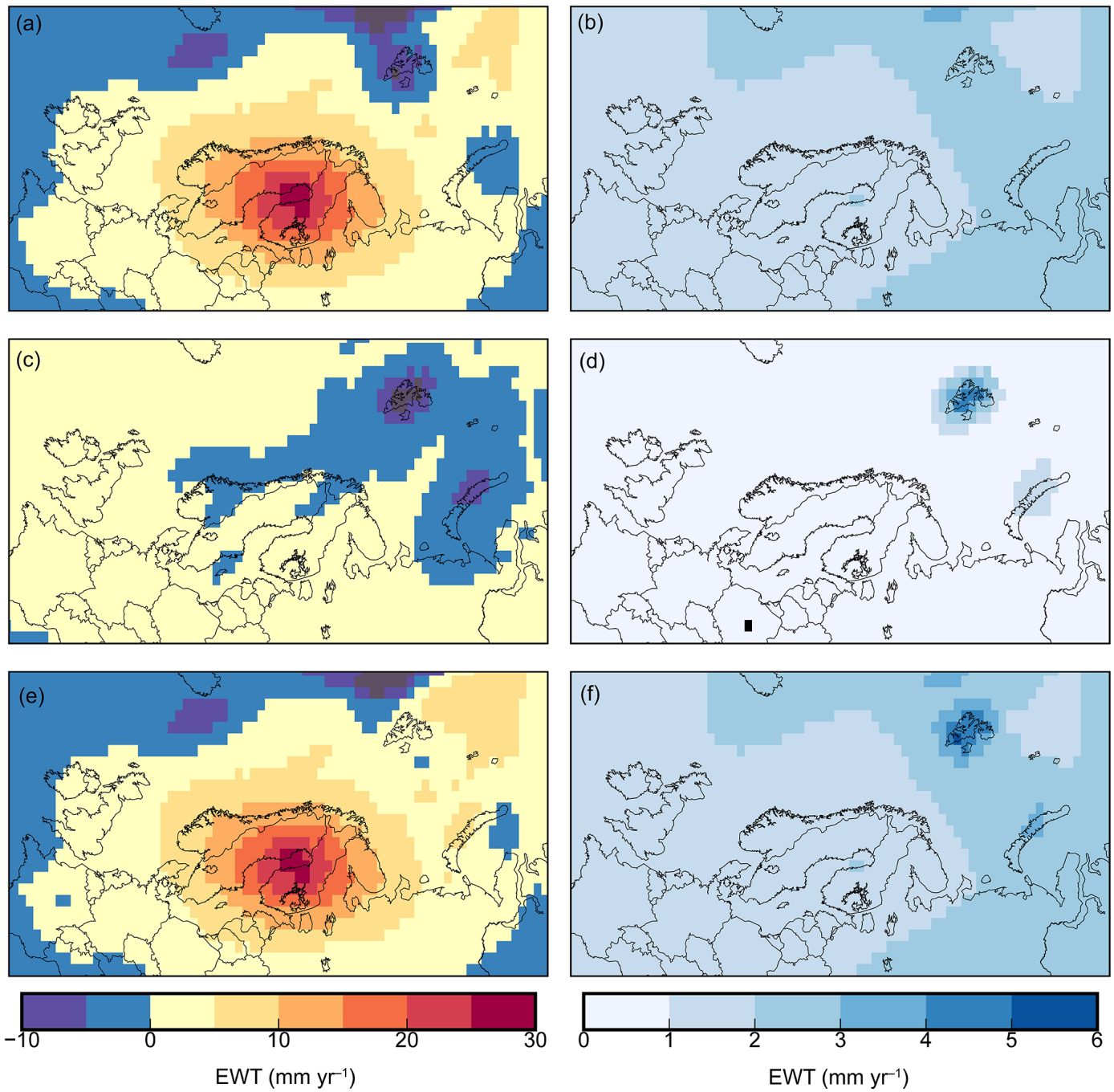

Figure 2. (a) Total gravity change rates measured from GRACE, (c) correction for terrestrial hydrology changes and present-day ice mass loss (Sect. 2.3), and (e) final corrected rates. (b, d, f) Same as (a, c, e) but rates are the $2 \sigma$ uncertainties associated with the signal. Units are $\mathrm{mm} \mathrm{yr}^{-1}$ change in equivalent water thickness (EWT).

either from glacial isostatic adjustment from the last glaciation or from the Little Ice Age (LIA). For both Svalbard and the Russian Arctic, we choose to apply an estimate that averages the ICESat and CryoSat estimates over the years 20032014 (Table 1). Subtracting these averaged rates from the total GRACE estimates for a similar time period (2003-2013; Schrama et al., 2014; Table 1) infers a reasonably consistent total solid Earth or GIA signal of $+6.6-7 \mathrm{Gt} \mathrm{yr}^{-1}$ in the region.

However, applying the averaged ice melt corrections to Svalbard and the Russian Arctic creates a large mass gain signal over these two areas and a relatively smaller signal in the central Barents Sea; this pattern is generally inconsistent with ice coverage in the Barents Sea region suggested by several different Pleistocene ice sheet reconstructions (Auriac et al., 2016), and it is therefore inconsistent with the paleo-
GIA signal that the input signal should represent. Possible explanations for this inconsistency are as follows: (i) models of LGM ice cover in the region require thicker ice over Svalbard and the Russian Arctic than in the Barents Sea; (ii) there is a large Little Ice Age GIA signal over these two regions; and/or (iii) the Wiener filter applied to the GRACE data too aggressively filters signal in these small regions. The first explanation is unlikely because glacial margin chronology suggests that Svalbard and the Russian Arctic were located on or near the margin of the Barents Ice Sheet where ice cover would have been thinnest. To counteract the effect of either of the latter two explanations (LIA rebound or signal loss in GRACE), we apply ad hoc scaling factors of 0.25 and 0.2 to the ice mass loss estimates in Svalbard and the Russian Arctic (Table 1), so that their removal from the total GRACE signal results in a spatial pattern in the residual 
Table 1. Estimates of present-day mass change for Svalbard, the Russian Arctic, and Scandinavia for different time periods and from different sources. Letters in parentheses indicate estimation method: gl - glaciological; I - IceSat; G - GRACE; C - CryoSat. All rates are in Gt yr ${ }^{-1}$.

\begin{tabular}{|c|c|c|c|}
\hline Study/source & Svalbard $\left(\mathrm{Gt} \mathrm{yr}^{1}\right)$ & Russian Arctic (Gtyr $\left.{ }^{1}\right)$ & Scandinavia $\left(\mathrm{Gtyr}^{1}\right)$ \\
\hline \multicolumn{4}{|l|}{ 2003-2009 } \\
\hline $\begin{array}{l}\text { Marzeion et al. (2015) } \\
\text { (2003-2009) }\end{array}$ & $-42.0 \pm 3.2(\mathrm{gl})$ & $-22.9 \pm 4.7(\mathrm{gl})$ & $-1.2 \pm 0.2(\mathrm{gl})$ \\
\hline $\begin{array}{l}\text { Gardner et al. (2013) } \\
(2003-2009) \\
\text { Wouters (2016) } \\
(2003-2009)\end{array}$ & $\begin{array}{r}-17.0 \pm 6.0(\mathrm{gl}) \\
-5.0 \pm 2.0(\mathrm{I}, \mathrm{G}) \\
-4.6 \pm 1.2(\mathrm{I})\end{array}$ & $\begin{array}{r}-21.0 \pm 13.0(\mathrm{gl}) \\
-11.0 \pm 4.0(\mathrm{I}, \mathrm{G}) \\
-10.5 \pm 1.3(\mathrm{I})\end{array}$ & $-2.0 \pm 0.0(\mathrm{gl})$ \\
\hline \multicolumn{4}{|l|}{ 2010-2014 } \\
\hline $\begin{array}{l}\text { Wouters (2016) } \\
\text { (2010-2014) }\end{array}$ & $-16.5 \pm 1.6(\mathrm{C})$ & $-14.9 \pm 1.2(\mathrm{C})$ & - \\
\hline \multicolumn{4}{|l|}{$\geq 10$-year time period } \\
\hline $\begin{array}{l}\text { Marzeion et al. (2015) } \\
\text { (2004-2013) }\end{array}$ & $-39.8 \pm 2.2(\mathrm{gl})$ & $-24.7 \pm 3.0(\mathrm{gl})$ & $-1.3 \pm 0.1(\mathrm{gl})$ \\
\hline $\begin{array}{l}\text { Average Wouters (2016) } \\
(2003-2014)\end{array}$ & $-10.6 \pm 2.0(\mathrm{I}, \mathrm{C})$ & $-12.7 \pm 1.8(\mathrm{I}, \mathrm{C})$ & - \\
\hline $\begin{array}{l}\text { Schrama et al. (2014) } \\
\text { (2003-2013) }\end{array}$ & $-4.0 \pm 0.7(\mathrm{G})$ & $-5.7 \pm 0.9(\mathrm{G})$ & $+1.3 \pm 0.9(\mathrm{G})$ \\
\hline This study & $-10.6 \pm 2.0(\mathrm{I}, \mathrm{C})$ & $-12.7 \pm 1.8(\mathrm{I}, \mathrm{C})$ & $-1.3 \pm 0.1(\mathrm{gl})$ \\
\hline This study, with scaling & $-2.7 \pm 2.0(\mathrm{I}, \mathrm{C})$ & $-2.5 \pm 1.8(\mathrm{I}, \mathrm{C})$ & $-1.3 \pm 0.1(\mathrm{gl})^{*}$ \\
\hline
\end{tabular}

* Not scaled

(i.e. paleo-GIA) signal that is approximately consistent with thicker LGM ice cover over the Barents Sea than around its margins (Fig. 2e). Such a scaling factor approach is certainly not ideal but serves to provide a GRACE input signal in the Barents Sea region that has a spatial pattern broadly consistent with expectations of the paleo-GIA response to loading and unloading from the Barents Ice Sheet.

\subsubsection{GPS}

Vertical land motion rates may likewise be affected by present-day ice mass loss and the terrestrial hydrology cycle. As with the GRACE data, the GPS data are corrected for changes to terrestrial hydrology south of $71.5^{\circ} \mathrm{N}$ latitude using predictions from the PCR-GLOBWB model, although here, the hydrology trend has been estimated from 1993-2014 to be more consistent with the length of the GPS time series. North of $71.5^{\circ} \mathrm{N}$ latitude, the same scaled corrections derived from ICESat and CryoSat are applied for present-day ice mass changes in Svalbard and the Russian Arctic. Throughout the study area, the GPS measurements are also corrected for additional elastic vertical motion from mass loss of the Greenland Ice Sheet, the Antarctic Ice Sheet, and glaciers and ice caps in northern Canada. Mass loss of the Greenland Ice Sheet is estimated from 1993 to 2014 using surface mass balance estimates from RACMO2.3 (Noël et al., 2015) and ice discharge with a constant acceleration of $6.6 \mathrm{Gtyr}^{-2}$ (van den Broeke et al., 2016). Mass loss of the Antarctic Ice Sheet is also estimated from 1993 to 2014 using RACMO2.3p1 and assuming a constant acceleration in ice discharge of $2 \mathrm{Gt} \mathrm{yr}^{-2}$ (van Wessem et al., 2016). The scenarios for both Greenland and Antarctica are consistent with the mass balance estimates from Shepherd et al. (2012). For the Canadian Arctic, a constant mass loss rate of $60 \mathrm{Gt} \mathrm{yr}^{-1}$ is used (Gardner et al., 2013). All trends and accelerations are calculated with annual time steps. The vertical elastic response is computed in the CM frame using a pseudo-spectral approach up to degree and order 360 and includes the effect of rotational feedback. The respective loads in each year are applied to a spherically symmetric Earth model (e.g. Farrell, 1972) using elastic Earth parameters from the Preliminary Reference Earth Model (Dziewonski and Anderson, 1981). Linear trends in the calculated vertical motion time series are then estimated by least squares over the years 1993-2014 for each region and finally summed to yield the total elastic response. All signals combine to yield a total net uplift of approximately $0.2-0.5 \mathrm{~mm} \mathrm{yr}^{-1}$ throughout most of the study area, with Greenland mass loss providing the largest contribution (Fig. 3). The additional uncertainties are also computed and added in quadrature to the measurement uncertainties; correction of the GPS data for non-GIA signals adds $< \pm 0.05 \mathrm{~mm} \mathrm{yr}^{-1}$ uncertainty in most of the study area and $\sim \pm 0.1 \mathrm{~mm} \mathrm{yr}^{-1}$ in Svalbard (Fig. 3). 

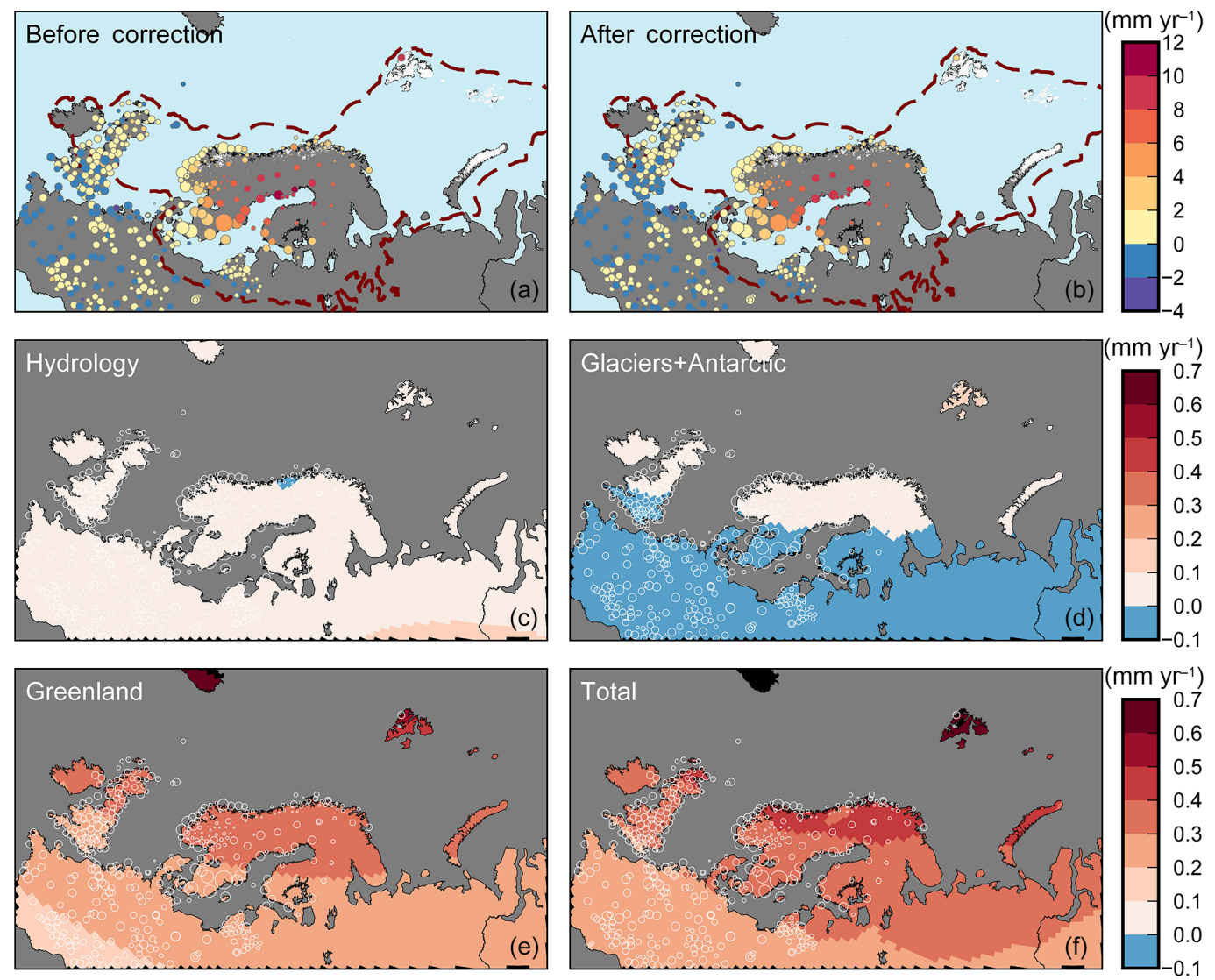

Figure 3. GPS-measured rates of vertical land motion before and after the applied elastic correction (a and b). An elastic correction is computed for mass loss from Greenland, the West Antarctic Ice Sheet (WAIS), glaciers and ice caps in northern Canada, Svalbard and the Russian Arctic, and loading from the terrestrial hydrology cycle. Sites on Svalbard are additionally corrected for LIA uplift as discussed in the text.

Finally, in addition to present-day ice mass loss signals, a correction of $4.33 \pm 0.40 \mathrm{~mm} \mathrm{yr}^{-1}$ is removed from the vertical motion rates for the two GPS sites on Svalbard (NYAL and LYRS). This value is an average of three scenarios from Mémin et al. (2014), which estimate the vertical land motion at Ny-Ålesund due to Pleistocene and Little Ice Age GIA signals; their estimates range from 3.31 to $4.95 \mathrm{~mm} \mathrm{yr}^{-1}$; thus, the averaged correction of $4.33 \mathrm{mmyr}^{-1}$ that is applied assumes that the signal from Pleistocene GIA is small and that most residual land motion here is from LIA rebound. After correction for present-day ice mass changes and approximated LIA uplift, the residual (inferred paleo-GIA) vertical uplift rates at NYAL and LYRS are $2.64 \pm 0.80$ and $1.10 \pm 2.64 \mathrm{~mm} \mathrm{yr}^{-1}$, respectively.

\subsection{A priori model information}

The prior model covariance matrix contains predictions from a set of forward GIA models that varies ice sheet history and mantle viscosity and is constructed as described in Hill et al. (2010) and Simon et al. (2017). Here, two different ice sheet histories are coupled to a suite of three-layer Earth models with an elastic lithosphere and varying upper and lower mantle viscosities.

The first ice sheet model is the global ICE-5G model (Peltier, 2004). We later compare the data-driven predictions to the more recent ICE-6G forward model (Peltier et al., 2015) (Sect. 3.3); without ICE-6G in the a priori information, the compared predictions are independent to the extent possible. In the second ice sheet model, the glacial history over Fennoscandia and the British Isles is described by the model(s) from the Australian National University (ANU; Lambeck et al., 2010). This second version of the ice sheet model contains ICE-5G coverage over Greenland and Antarctica and the model of North American coverage presented in Simon et al. $(2015,2016)$. Tests indicate that varying the ice sheet history over North America has little impact on the predictions in Fennoscandia, although this variation is useful for studies that wish to expand the study area outside of the current study area. Relative to ICE-5G, LGM ice cover in the ANU model is thinner over the Barents Sea, thicker over Svalbard and Scotland, and discontinuous between Scandinavia and the British Isles (Fig. 4). 

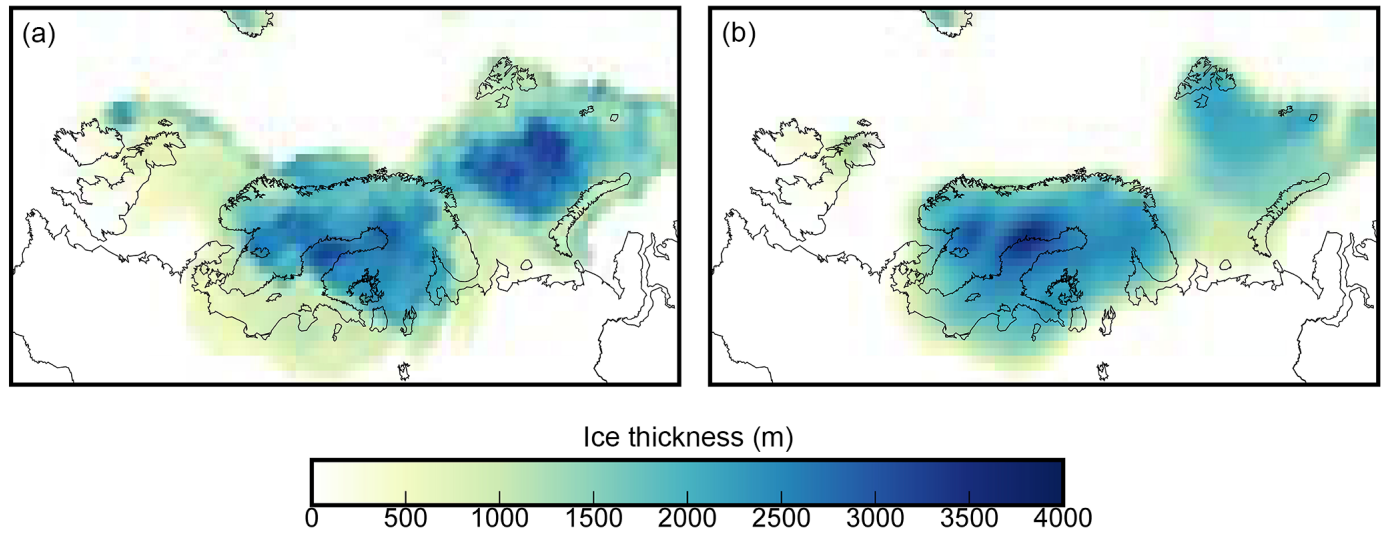

Figure 4. Last Glacial Maximum (LGM) ice cover in Scandinavia, the Barents Sea, and the British Isles from ICE-5G (a) and the ANU model (b).

Previous GIA modelling studies can be used to infer a range of reasonable Earth model parameters for the a priori model set. Steffen and Wu (2011) reviewed the results of several GIA modelling studies of the Fennoscandian region and indicated that these analyses suggest regional upper mantle viscosities of between 0.1 and $1 \times 10^{21} \mathrm{Pas}$ and lower mantle viscosities approximately 1 to 2 orders of magnitude larger (so $1-100 \times 10^{21} \mathrm{Pas}$ ). They further indicated that lithospheric thickness in Fennoscandia is likely variable with values ranging from 80 to $200 \mathrm{~km}$ (Steffen and $\mathrm{Wu}$, 2011). Studies that have followed Steffen and Wu's (2011) review infer slightly narrower ranges for Earth parameters in Fennoscandia. Depending on the ice sheet history and data constraints, the studies of Zhao et al. (2012), Kierulf et al. (2014), Schmidt et al. (2014), and Patton et al. (2017) infer values of upper mantle viscosity, lower mantle viscosity, and lithospheric thickness that may range from (or lie within) 0.34 to $3 \times 10^{21} \mathrm{Pas}, 3$ to $50 \times 10^{21} \mathrm{Pas}$, and 93 to $160 \mathrm{~km}$, respectively. In the British Isles, Kuchar et al. (2012) infer upper and lower mantle viscosities of $3 \times 10^{21}$ and $2 \times 10^{22} \mathrm{Pas}$, respectively, consistent with the values inferred by Bradley et al. (2011). Both studies find a best-fit lithospheric thickness of $71 \mathrm{~km}$ in this region. In the Barents Sea region, Auriac et al. (2016) summarize the performance of six ice sheet models; the four best-fitting models infer respective upper and lower mantle viscosities of $0.2-2 \times 10^{21}$ and $1-50 \times 10^{21} \mathrm{Pas}$ and lithospheric thicknesses of $71-120 \mathrm{~km}$. Both the studies of Root et al. (2015) and Patton et al. (2017) infer Earth parameters for this region that are within the ranges given by Auriac et al. (2016).

Considering these three regions as a whole gives minimum to maximum ranges for upper and lower mantle viscosity and lithospheric thickness of $0.2-3 \times 10^{21}$ and $3-50 \times 10^{21} \mathrm{Pas}$ and $71-160 \mathrm{~km}$. These mantle viscosity ranges are consistent with those used in our prior model set, which range from 0.2 to $2 \times 10^{21}$ and 1 to $60 \times 10^{21} \mathrm{Pas}$ in the upper and lower mantle. The prior model set uses an elastic lithospheric thickness of $90 \mathrm{~km}$, although future analyses could benefit from the use of a wider range of thicknesses. With regard to the mantle viscosities, we note that both the ICE-5G and ANU ice sheet models were not developed independently from a description of mantle viscosity. While the coupling of a set of differing Earth models to a "tuned" ice sheet history may introduce artificially high variances, this concern may be countered by considering that the variances in such an a priori Earth-ice model set could almost certainly be made larger if any combination of 3-D Earth structure, non-linear mantle rheology, or glaciological and climatological constraints were additionally incorporated. A full covariance matrix is generated that relates the variances of each model prediction relative to the suite's average. All models are represented at spherical harmonic degree and order 256 . The average response and uncertainties of the a priori set is shown in Fig. 5.

\subsection{Method}

The least-squares adjustment method is based on the methodology of Hill et al. (2010) and extended by Simon et al. (2017). The method simultaneously inverts the data constraints (GPS, GRACE, or both) with the a priori GIA model information and minimizes the misfit to both input types. As in Simon et al. (2017), variance component estimation (VCE) is also used to weight the input uncertainties. The prior models are combined with the data in three scenarios: inversion with the GPS data alone (D1), inversion with the GRACE data alone (D2), and inversion with both datasets (D3). 

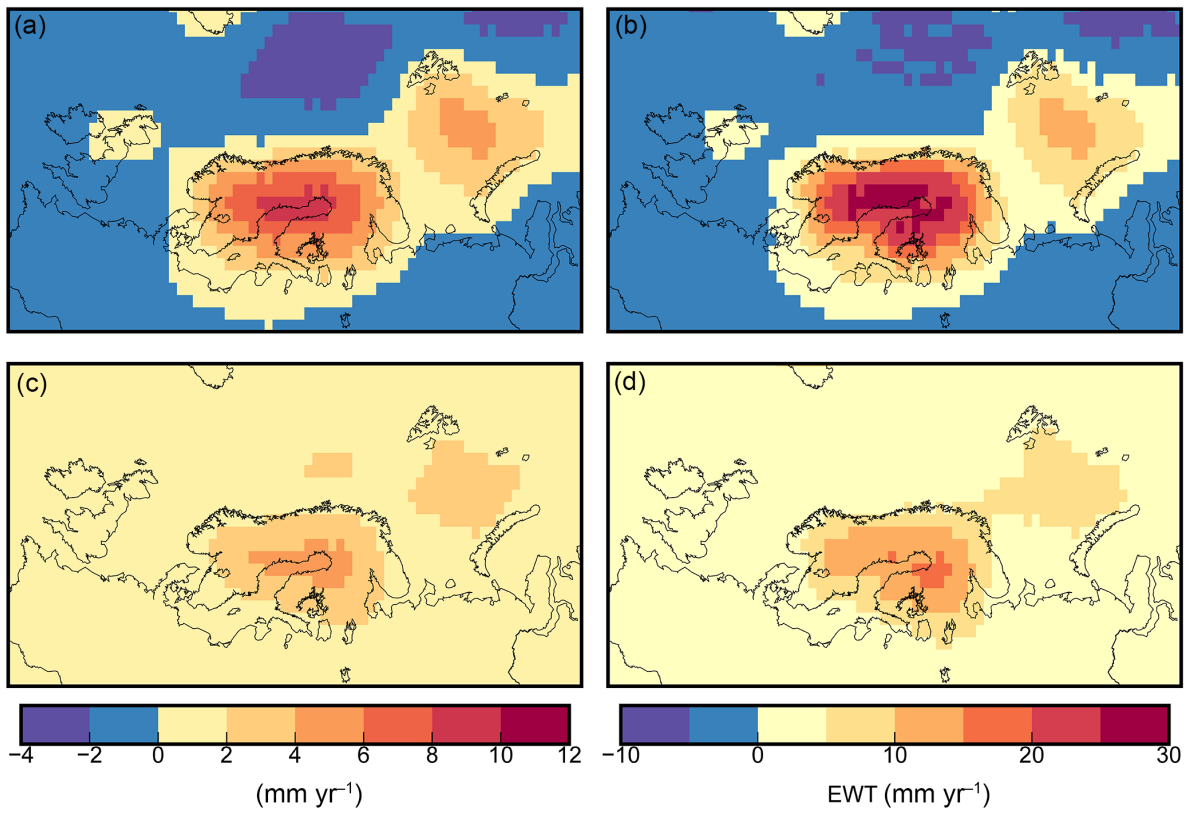

Figure 5. Averaged a priori rates of the Earth-ice model set. (a, c) Vertical rates and uncertainties. (b, d) Gravity change rates and uncertainties in units of equivalent water thickness (EWT) change.

\section{Results and discussion}

\subsection{Prediction of vertical motion and gravity change}

\subsubsection{Vertical motion}

The predicted GIA response and uncertainties for the D1D3 scenarios are shown for vertical land motion (Fig. 6). The incorporation of the GPS data in scenarios D1 and D3 leads to a similar pattern of regional uplift although relative to D1, the D3 scenario predicts slightly lower rates of uplift over the northern British Isles and in the Barents Sea. D1 and D3 have respective peak uplift rates of 9.8 and $9.2 \mathrm{~mm} \mathrm{yr}^{-1}$. When only the gravity data are inverted in the D2 scenario, the region of uplift is broader and the peak uplift rate is smaller at $7.1 \mathrm{~mm} \mathrm{yr}^{-1}$. In all cases, the peak uplift is centred over the northwestern region of the Gulf of Bothnia. The peak $(1 \sigma)$ uncertainty rates are $\pm 0.36, \pm 0.43$, and $\pm 0.28 \mathrm{~mm} \mathrm{yr}^{-1}$ for the D1-D3 cases. Similar to the results of Simon et al. (2017), the predicted uncertainties are largest where the signal is largest (around the Gulf of Bothnia) and/or the data coverage is sparsest and most poorly constrained (around the Barents Sea). In Finland, for example, the relatively large signal and the relatively sparse data coverage combine to create a region of larger uncertainty than in surrounding areas. The inclusion of VCE does not significantly impact the signal prediction but in general somewhat increases the estimated a posteriori model uncertainty; the weighting factors determined by VCE are shown in Table 2 . In model D1, both the uncertainties of the vertical velocities and the prior model set are slightly reduced. In model D3, the uncertainties of the vertical velocities are basically unscaled (increased by a factor of 1.02) whereas the covariances of the prior model set are reduced by a factor of 0.64 (note, however, that the original covariances of the prior model set are still generally larger than those of the vertical data, at least in the region of the former load centre).

\subsubsection{Gravity change}

The predicted gravity change rates for D1-D3 are comparable to the predicted vertical motion rates in both the spatial pattern and relative magnitude (not shown). The peak mass change rates are again centred over the northern Gulf of Bothnia, and are 33.7, 24.3, and $32.3 \mathrm{~mm} \mathrm{yr}^{-1}$ of equivalent water thickness change for the D1-D3 scenarios. The peak associated $1 \sigma$ uncertainties are $\pm 1.59, \pm 1.59$, and $\pm 1.22 \mathrm{mmyr}^{-1}$ EWT. In both the D2 and D3 models, the uncertainties of the GRACE data are increased by the VCE analysis (Table 2).

\subsection{Misfit values and residuals}

For both $\chi^{2}$ and rms values, the D1 model provides the best fit to the vertical data, the D2 model provides the best fit to the gravity data, and the D3 model provides the best fit overall (Fig. 7). The $\chi^{2}$ values of the vertical prediction for both D1 and D3 are approximately equal to 1 . The $\chi^{2}$ values for the gravity data are relatively large with the smallest value of 15.9 obtained for the D2 model. Scaling the gravity data uncertainties by the VCE-determined scaling factors in Table 2 reduces the overall $\chi^{2}$ values for the gravity prediction 
(a)
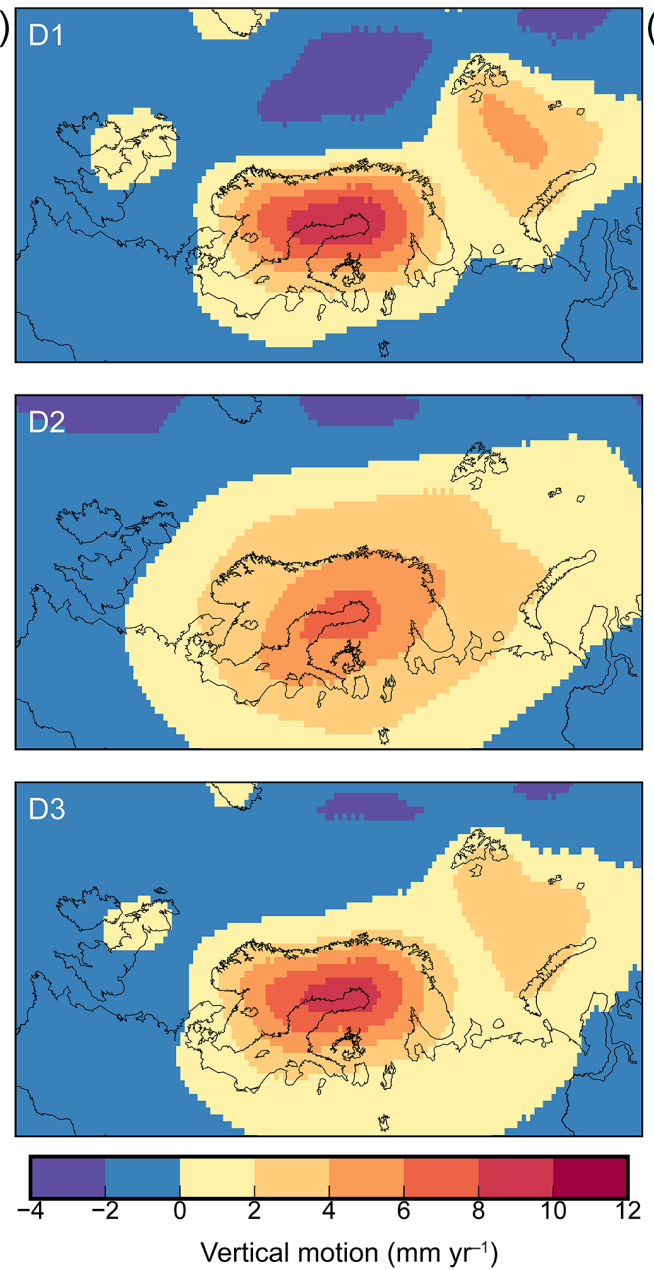
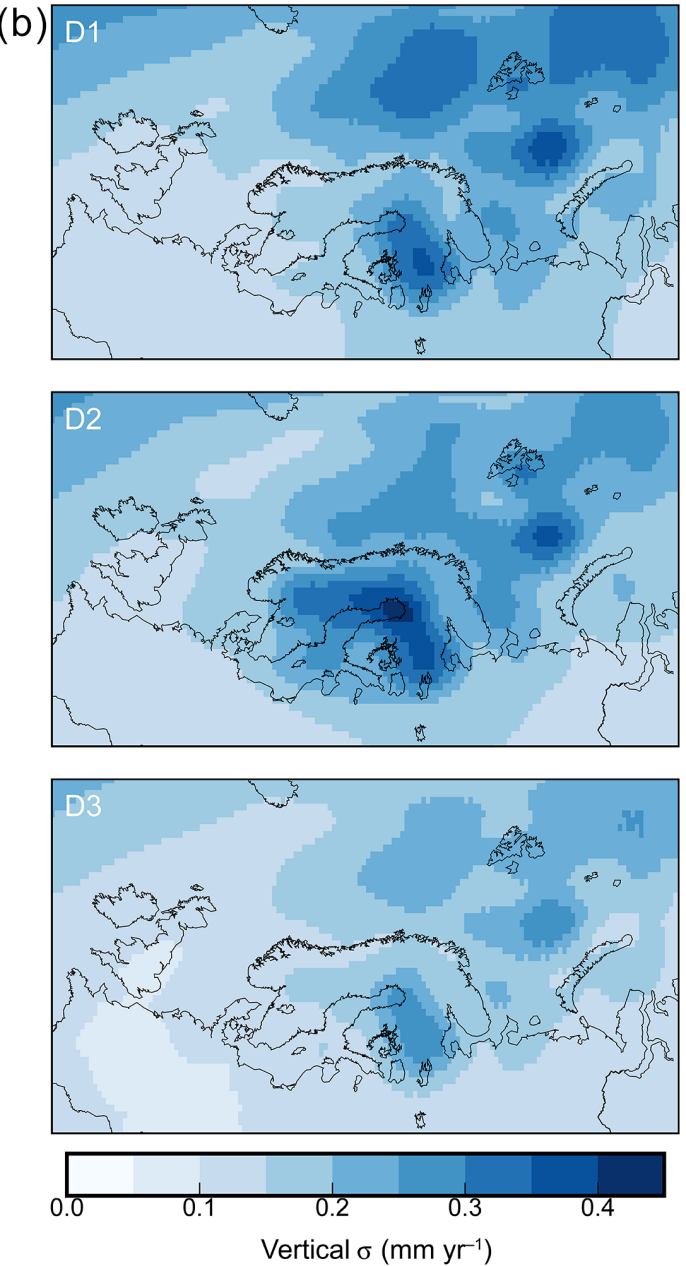

Figure 6. Prediction of present-day vertical land motion (a) and uncertainties (b) due to long-term GIA for the D1-D3 scenarios.

Table 2. Results of the variance component analysis. $\sigma_{1}^{2}$ and $\sigma_{2}^{2}$ are the variance factors applied to the vertical motion data (dataset 1) and gravity change data (dataset 2), respectively, and $\sigma_{\mu}^{2}$ is the variance factor applied to the prior information. The ratios describe how each input covariance matrix is weighted relative to the other(s).

\begin{tabular}{lrrr|rr}
\hline & \multicolumn{3}{c|}{$\sigma^{2}$ Value } & \multicolumn{2}{c}{ Ratios } \\
\cline { 2 - 6 } Data incorporated & $\sigma_{1}^{2}$ & $\sigma_{2}^{2}$ & $\sigma_{\mu}^{2}$ & $\sigma_{1}^{2} / \sigma_{2}^{2}$ & $\sigma_{1}^{2} / \sigma_{\mu}^{2}, \sigma_{2}^{2} / \sigma_{\mu}^{2}$ \\
& (Vertical) & (Gravity) & (Prior) & & \\
\hline D1: vertical only & 0.85 & - & 0.94 & - & $0.90,-$ \\
D2: gravity only & - & 13.51 & 0.61 & - &,- 22.15 \\
D3: vertical + gravity & 1.02 & 20.55 & 0.64 & 0.05 & $1.59,32.11$ \\
\hline
\end{tabular}

to approximately 1.2 for the D2 and D3 models. However, the statistical fit of the models to the gravity data remains generally worse than the fit to the vertical motion data.

Figures 8 and 9 summarize the spatial residuals for the best-fit D3 model and the binned residuals for all models. The vertical motion residuals are unbiased and generally small. Regionally, the D3 model underpredicts vertical mo- tion in Scotland and conversely overpredicts vertical motion along parts of the southern Norwegian coast and the Netherlands. The gravity residuals for D3 are relatively low for much of the study area, although there is noticeable overprediction in central Scandinavia and in the Barents Sea. 

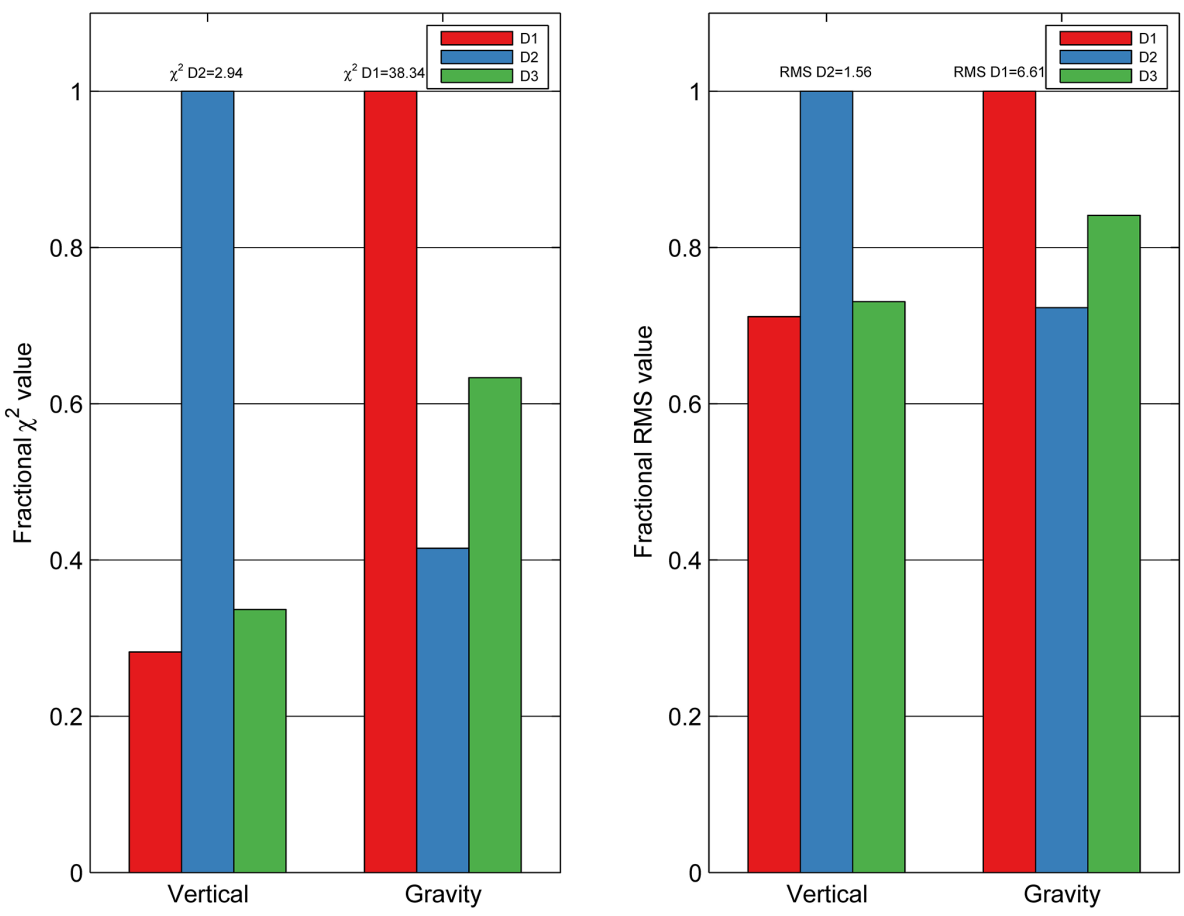

Figure 7. Fractional $\chi^{2}$ and rms values for each of the D1-D3 models. Fractional values are determined relative to the value of the worstfitting model for both the vertical motion and gravity change predictions (i.e. fractional $\chi^{2}$ values of the vertical motion prediction are relative to $\mathrm{D} 2$, for which $\left.\chi^{2}=2.94\right)$. $\chi^{2}$ values are not VCE-scaled; see Fig. 8 for all $\chi^{2}$ values including with and without VCE scaling, where applicable.

\subsection{Comparison of vertical motion prediction to other models}

We compare the vertical motion prediction of D1 to two other models. The first model is the forward GIA model ICE-6G (Peltier et al., 2015), which is constrained by a global dataset of vertical land motion measurements. The majority of the these data are GPS measurements from the global solution of JPL; within the study area of Scandinavia and northern Europe, additional measurements come from the BIFROST GPS network as well as a small number of satellite laser ranging (SLR), Doppler orbitography and radiopositioning integrated by satellite (DORIS), and very long baseline interferometry (VLBI) measurements (Argus et al., 2014; Peltier et al., 2015). The second model is the semi-empirical land uplift model NKG2016LU (Vestøl et al., 2016) designed by several researchers in collaboration with the Nordic Geodetic Commission (NKG). This model is constrained with GPSmeasured vertical land motion rates updated from the dataset of Kierulf et al. (2014), levelling measurements, and GIA model predictions and provides a semi-empirical estimate of total present-day vertical land motion.

Figure 10 compares the vertical land motion predictions of D1, ICE-6G, and NKG2016LU. The ICE-6G comparison is made relative to the vertical motion dataset presented in this paper, although as stated above, it was constrained with a different variant of regional vertical land motion data. In addition, NKG2016LU predictions are available on a smaller grid and provide the best fit to data from Scandinavia and the Baltic countries; thus, we limit our comparison with this model to north of $55^{\circ} \mathrm{N}$ (reducing the comparison dataset from 459 to 185 sites).

With no significant bias and a $\chi^{2}$ value of less than 1 , the D1 model provides a good fit to the data. As with the D3 model, the D1 model underpredicts vertical motion over the northern British Isles and appears also to overpredict vertical motion around the Netherlands. The ICE-6G model underpredicts vertical motion at several sites in Scandinavia and has an overall $\chi^{2}$ value of 1.33 , somewhat higher than that of D1. At station NYAL on Svalbard, both the D1 and ICE-6G models underpredict vertical motion by more than $2 \mathrm{~mm} \mathrm{yr}^{-1}$, even after the applied corrections for present-day mass loss and possible LIA uplift. When the NKG2016LU model is evaluated relative to the GPS data without an elastic correction applied, the $\chi^{2}$ value is less than 1 , similar to D1. Figure 10 shows the difference in the prediction of vertical motion between NKG2016LU and D1. The former has consistently higher predicted uplift rates over the study area, with an average difference of $+0.3 \mathrm{~mm} \mathrm{yr}^{-1}$, which is primarily the result of applying the elastic correction to the data used in the D1 model. To the extent that is possible, D1 is, therefore, an estimate of the paleo-GIA signal rather 

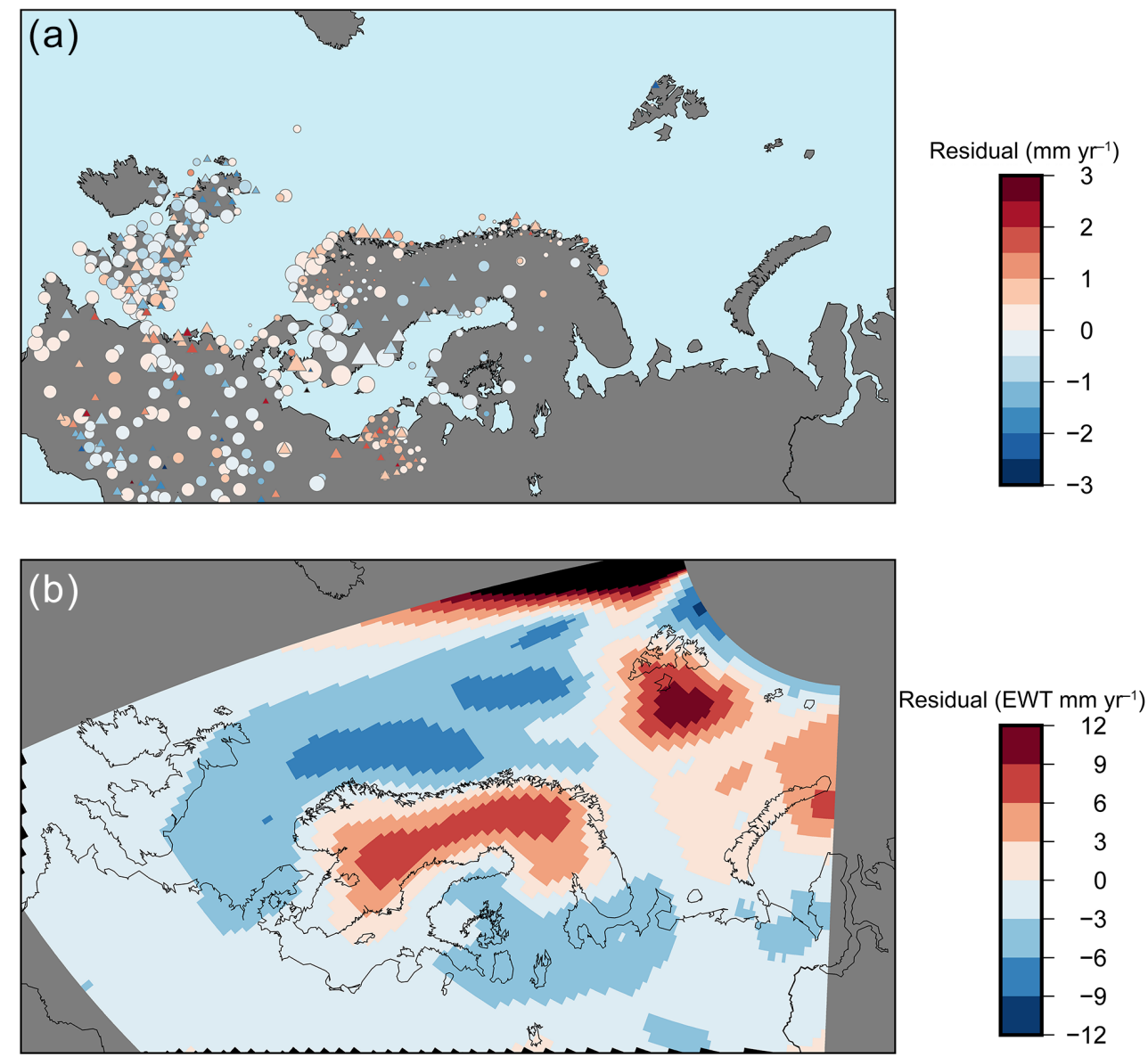

Figure 8. Spatial residuals for the D3 model for vertical motion (a) and gravity change (b). In (a), triangles indicate that model prediction is outside the $1 \sigma$ uncertainty of the measurement; circles indicate that model prediction is inside the $1 \sigma$ uncertainty of the measurement.

than the total uplift signal. The fact that the statistical fit to the data of both D1 and NKG2016LU is slightly better than the fit of the ICE-6G forward model is expected due to the fundamental difference in model type: unlike ICE-6G, both of the semi-empirical models explicitly incorporate the data into the prediction via formal inversion. Conversely, an advantage of ICE-6G and other models of its type is the direct insight they offer into the space-time evolution of the ice sheets, which cannot be inferred from a present-day empirical prediction alone.

\subsection{Tide gauge comparison}

To assess the effect of GIA on regional sea-level change, we remove model D1's predictions of long-term GIA from mean sea-level trends at 13 tide gauge sites along the coast of the North Sea and 7 tide gauge sites along the Norwegian coast (Figs. 11 and 12). The sea-level trends are taken from Frederikse et al. (2016), who estimated the rates at Permanent Service for Mean Sea Level (PSMSL) sites over the time interval 1958-2014. We also compare the effect of removing the modelled relative sea-level rates of ICE-6G at the same PSMSL locations. For both the North Sea and the Norwegian coastline, application of the D1 long-term sea-level trends to the total sea-level trends reduces the interstation variability and infers a similar rate of non-GIA sea-level change (1.89 and $1.84 \mathrm{~mm} \mathrm{yr}^{-1}$, respectively).

\subsubsection{North Sea}

When corrected for the D1 long-term GIA trends, which are assumed to be linear over decadal timescales, the standard deviation $(\mathrm{SD})$ of the trends decreases somewhat from 0.81 to $0.71 \mathrm{~mm} \mathrm{yr}^{-1}$. The D1 GIA correction is small at most sites, and at all sites except 7-9 (Hirtshals, Tregde, and Stavanger), the averaged sea-level trends appear dominated by processes other than long-term GIA (Fig. 11). At Hirtshals, Tregde and Stavanger, which are located nearest to the centre of the former FIS, the predicted GIA-induced sea-level trend is more than twice the magnitude of the averaged sealevel trend, and removing the GIA signal shifts the original trend at these locations closer to the mean of the 13 loca- 

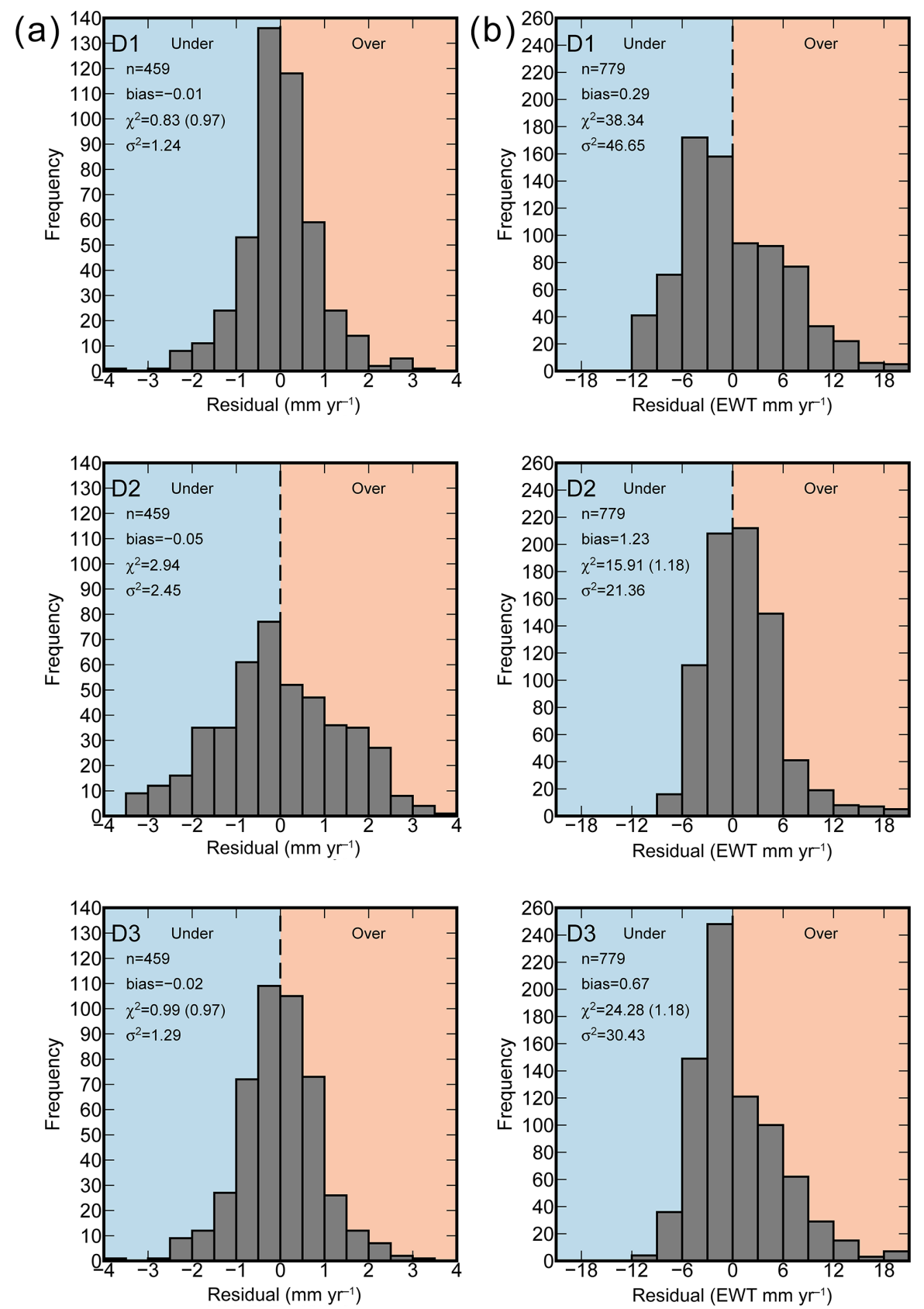

Figure 9. Histogram of residuals for models D1-D3, for prediction of vertical motion (a) and gravity change (b). Pink and blue shading indicate model overprediction and underprediction, respectively. Where given, $\chi^{2}$ values in brackets show the VCE-scaled $\chi^{2}$ value.

tions. When the ICE-6G rates are removed from the sealevel trends, the interstation variability and SD (from 0.81 to $0.83 \mathrm{~mm} \mathrm{yr}^{-1}$ ) are relatively unchanged. Regionally, the average D1 GIA model trend is $\sim-0.45 \mathrm{~mm} \mathrm{yr}^{-1}$ for the North Sea, which is larger in magnitude than the ICE-6G GIA trend of $\sim 0.06 \mathrm{~mm} \mathrm{yr}^{-1}$ in the North Sea. This difference may in part be due to the influence of the ANU ice sheet model in the prior model, which predicts stronger subsidence over the North Sea than either ICE-5G or ICE-6G. Accordingly, re- moval of the GIA signal from all 13 locations changes the North Sea mean sea-level trend from 1.39 to $1.84 \mathrm{~mm} \mathrm{yr}^{-1}$ for D1 and to $1.33 \mathrm{~mm} \mathrm{yr}^{-1}$ for ICE-6G. Station Lerwick is particularly discrepant; removing it from the comparison decreases the SD of the non-GIA rates to $0.45 \mathrm{~mm} \mathrm{yr}^{-1}$ for D1 and $0.75 \mathrm{~mm} \mathrm{yr}^{-1}$ for ICE-6G. The variability at Lerwick is insensitive to the application of the relatively small and linear GIA correction for this region and cannot be explained by GIA-induced sea-level change. Conversely, the variability in 


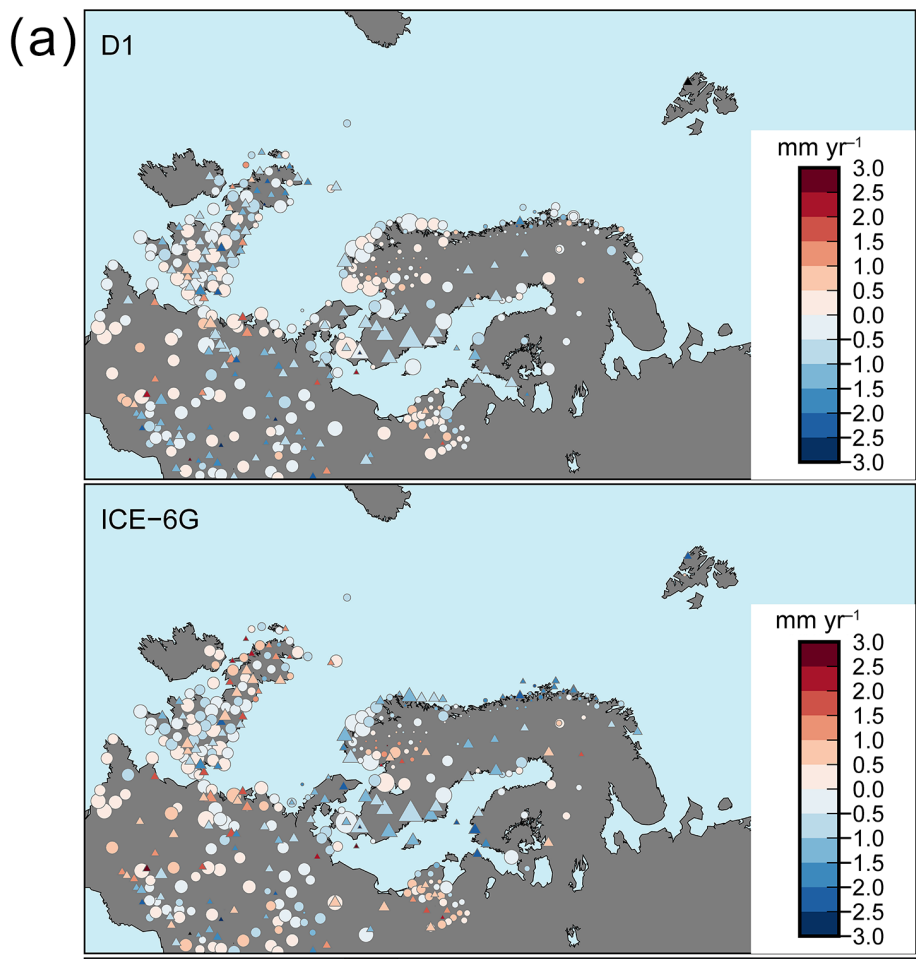

(b)
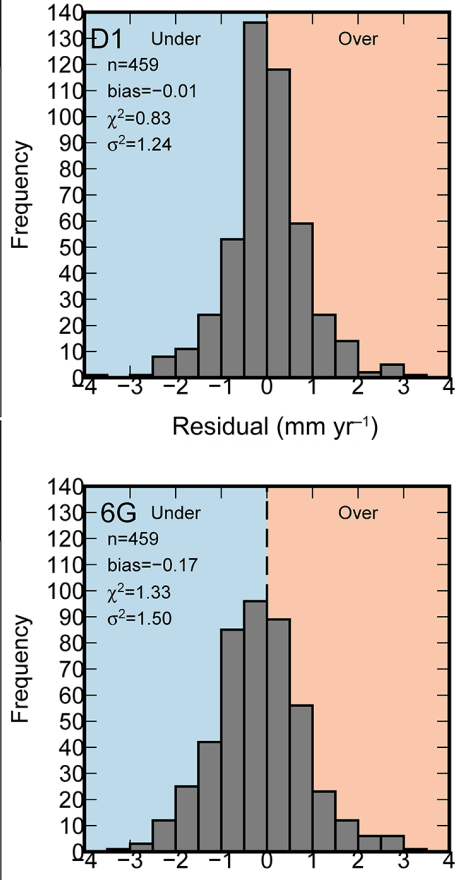

Residual $\left(\mathrm{mm} \mathrm{yr}^{-1}\right)$
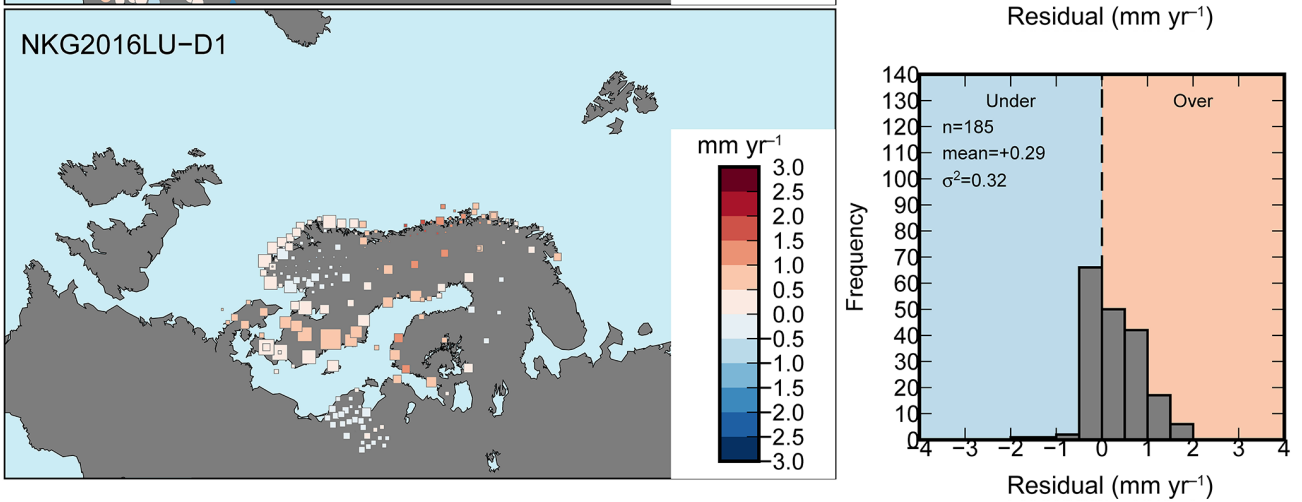

Figure 10. Spatial (a) and binned (b) vertical motion residuals for D1 and ICE-6G and the difference between the NKG2016LU and D1 models. Triangles indicate that model prediction is outside the $1 \sigma$ uncertainty of the measurement; circles indicate that model prediction is inside the $1 \sigma$ uncertainty of the measurement; squares show the difference between the two models (bottom panel in column a).

sea-level trends in the northeast North Sea, near the former FIS, is easily attributed to GIA for model D1.

\subsubsection{Norwegian coast}

The average sea-level trend for the seven sites along the Norwegian coast is $-0.22 \mathrm{~mm} \mathrm{yr}^{-1}$, with a SD of $0.87 \mathrm{~mm} \mathrm{yr}^{-1}$. Removal of the D1 long-term GIA trends increases the average sea-level trend to $1.89 \mathrm{~mm} \mathrm{yr}^{-1}$ and reduces the interstation variability $\left(0.44 \mathrm{~mm} \mathrm{yr}^{-1} \mathrm{SD}\right)$ (Fig. 12). The same is true for ICE-6G, although the magnitude of the changes are smaller $\left(0.44 \mathrm{~mm} \mathrm{yr}^{-1}\right.$ mean, $\left.0.65 \mathrm{~mm} \mathrm{yr}^{-1} \mathrm{SD}\right)$. This difference is owing to the relatively larger average GIA-related relative sea-level change for $\mathrm{D} 1\left(-2.11 \mathrm{~mm} \mathrm{yr}^{-1}\right)$ compared to ICE-6G $\left(-0.66 \mathrm{~mm} \mathrm{yr}^{-1}\right)$. The gradient of predicted GIA changes across the Norwegian coastline is steep, so the results may also be sensitive to the resolution of the GIA models.

\section{Conclusions}

We generate a data-driven prediction of the long-term GIA response at present day in Scandinavia, northern Europe, and the Barents Sea through the simultaneous inversion of GPSmeasured vertical motion rates, GRACE-measured gravity change rates, and a priori GIA model information. In models D1-D3, we predict GIA motions for the inversion of the ver- 

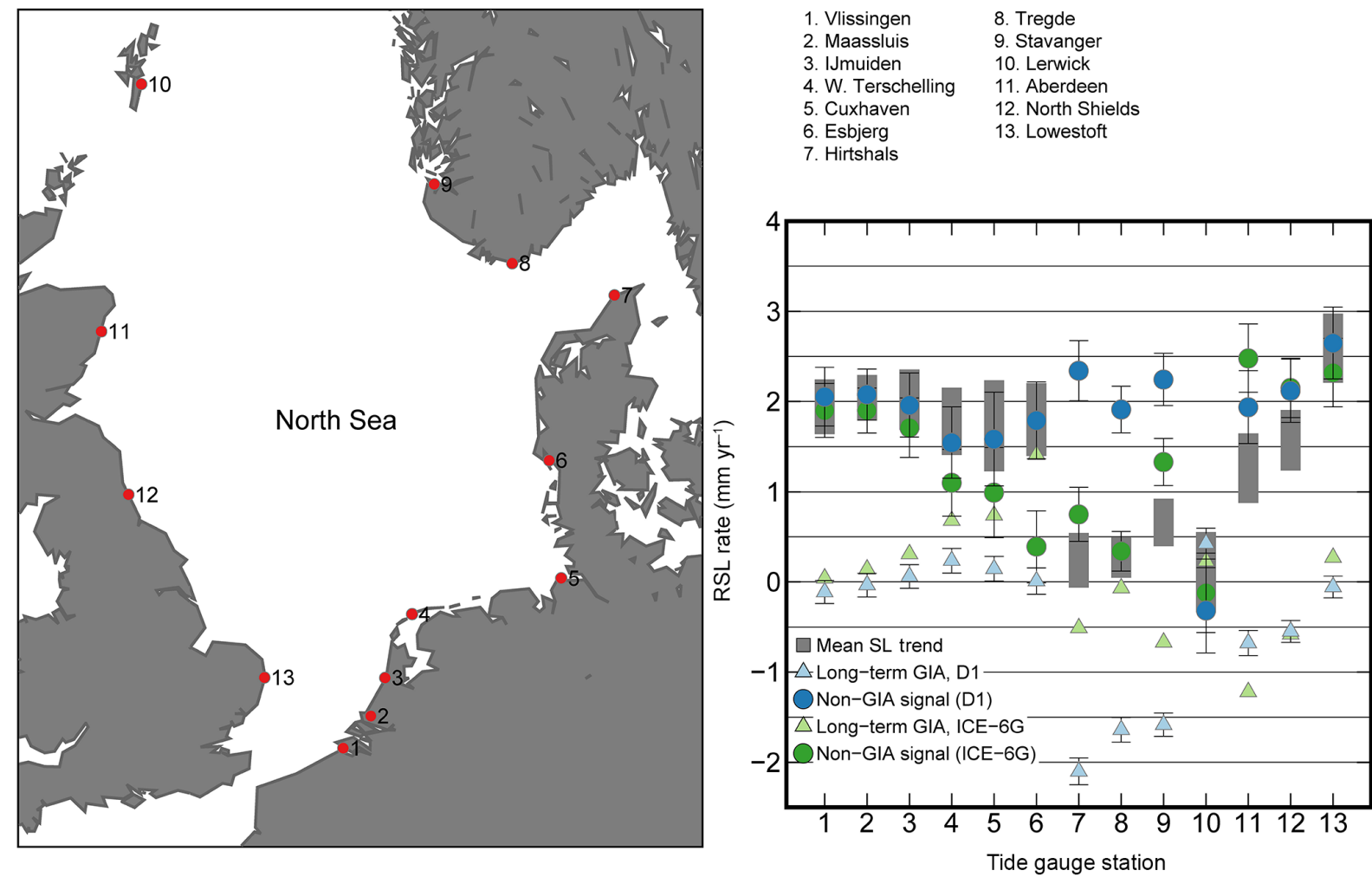

Figure 11. Comparison of mean total, long-term GIA, and non-GIA sea-level trends (grey boxes, triangles, circles) for 13 tide gauge stations in the North Sea. Long-term GIA trends are from model D1 and ICE-6G; mean sea-level trends are from Frederikse et al. (2016).

tical motion data, the gravity data, and both datasets. In both the $\chi^{2}$ and rms sense, the vertical motion data alone have the poorest ability to predict gravity change and vice versa. Predictions of the D3 model provide the best overall fit to both datasets.

In general, prediction of the gravity signal is problematic, with larger $\chi^{2}$ values than those obtained for the vertical motion prediction. The poorer prediction of gravity change is in part due to the uncertainty of the present-day mass loss effect in the Barents Sea region. The mass loss signal estimated by GRACE over Svalbard and the Russian Arctic is significantly smaller than estimates obtained from satellite altimetry. This difference may be the result of signal loss in the GRACE data from application of the Wiener filter or may also indicate that there is a non-zero component of ongoing glacial isostatic adjustment from the LIA.

The vertical motion signal is overall better predicted than the gravity signal. Both the D1 and D3 models have $\chi^{2}$ values of $\leq 1$ and predict rates of vertical motion that are within the $1 \sigma$ uncertainty of the observations throughout most of the study area. Regions of misfit persist in Scotland and around the Netherlands, where the model underpredicts and overpredicts rates of vertical motion, respectively. The misfit in Scotland may be partly due to both positive and negative rates of vertical motion that are present in the data over rel- atively short distances. Further analysis and filtering of the GPS dataset may be useful in this region. In the Netherlands, Kooi et al. (1998) found that present-day subsidence from sediment compaction as well as tectonic movements may contribute significantly to vertical land motion; correction for these effects may serve to reduce some of the residuals in this region. There may also be significant neotectonic movements in central Norway (Kierulf et al., 2014), which may explain some of the misfits that remain mainly along the central Norwegian coastline (Fig. 8).

The prediction of vertical land motion has a small but nonnegligible sensitivity to the application of an elastic correction. The elastic correction applied in this study is between 0.2 and $0.5 \mathrm{~mm} \mathrm{yr}^{-1}$; the largest contribution comes from mass loss of the Greenland Ice Sheet which yields regional uplift with a southeastward decreasing gradient. When the model predictions from another semi-empirical model of vertical motion, NKG2016LU, are compared to D1, a small but relatively uniform difference of $+0.3 \mathrm{~mm} \mathrm{yr}^{-1}$ is present in the model predictions over Scandinavia. Both NKG2016LU and D1 (and D3) have vertical motion $\chi^{2}$ values $\leq 1$ over their respective study areas. However, while the magnitude of the difference is smaller than the observational uncertainty on many of the measurements, it is generally larger than the estimated a posteriori model uncertainty. Also, because only 


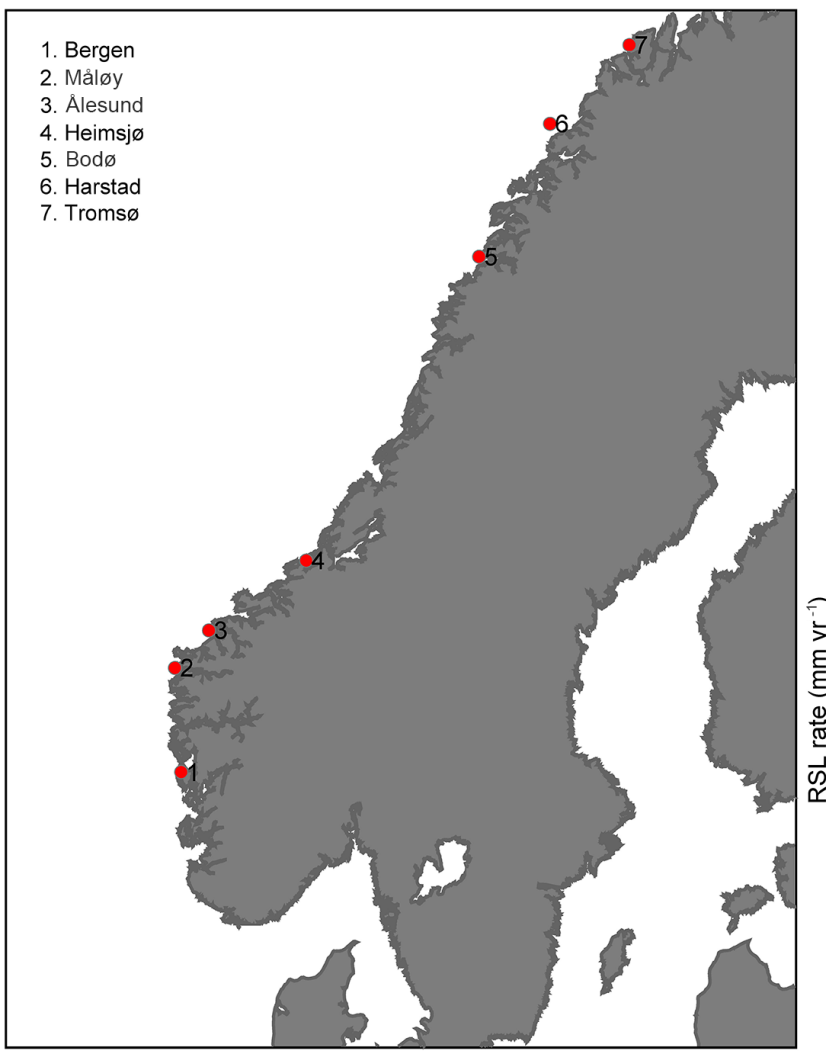
Mean SL trend
$\triangle$ Long-term GIA, D1
Non-GIA signal (D1)
$\triangle$ Long-term GIA, ICE-6G
Non-GIA signal (ICE-6G)

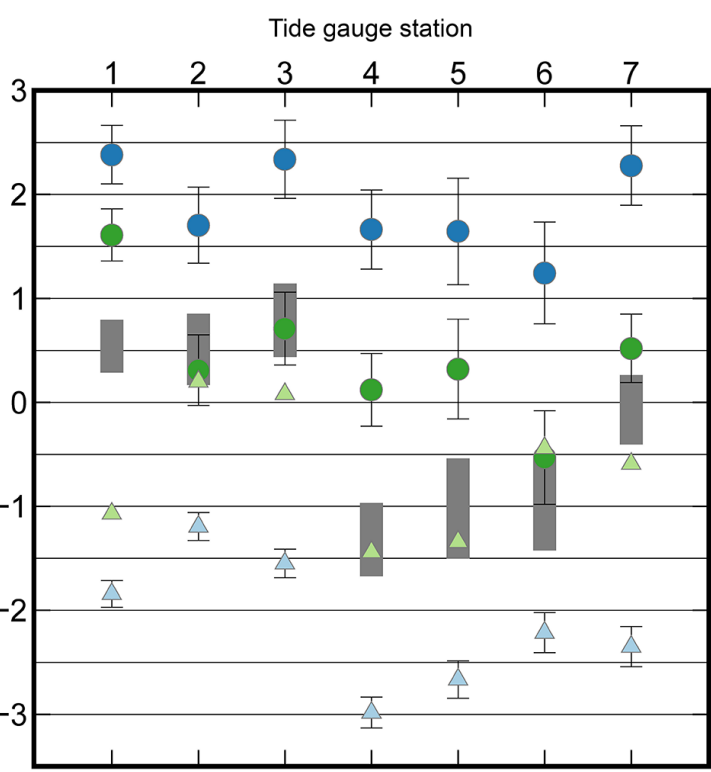

Figure 12. Same as caption for Fig. 11, except for tide gauge locations along the Norwegian coastline.

anthropogenic hydrological signals (and not natural hydrological signals) were included in the elastic correction, it is possible that the applied elastic correction is conservative in this region.

Therefore, the presence of such a difference in the vertical motion prediction suggests that while long-term GIA is the dominant contributor to vertical motion in central Scandinavia, it is still worthwhile correcting GPS land motion rates for present-day elastic signals, so long as these signals are adequately approximated (e.g. Riva et al., 2017). This conclusion, however, highlights a fundamental assumption that underpins the data-driven methodology: that the input data can be adequately "cleaned" for processes not arising from long-term GIA. Even with applied corrections for hydrology and contemporary ice mass loss, this assumption may not always be adequate, especially in regions where model misfits relative to the data are spatially coherent. Thus, the success of data-driven GIA predictions is evaluated by two criteria: (i) the estimation of realistic a posteriori uncertainties that are smaller than those associated with a priori knowledge and measurement uncertainty and (ii) the ability of the final model to provide a good fit to the data. The vertical motion predictions of models D1 and D3 satisfy both criteria for most of the study area and can thus provide a useful tool with which to separate long-term GIA signals from shorterterm forcing.

Data availability. Gridded vertical land motion predictions for the D1 model are available at the 4TU Centre for Research Data repository: https://data.4tu.nl/, https://doi.org/10.4121/uuid:4a495bbc0478-483a-baef-19ff34103dd2 (Simon et al., 2018). 


\section{Appendix A}

The 31 GPS measurements that are common to the Kierulf et al. (2014) and Nevada Geodetic Laboratory (Blewitt et al., 2016) datasets are shown in Fig. A1. The individual anthropogenic hydrology and glacial mass change contributions to the GRACE correction are shown in Fig. A2.

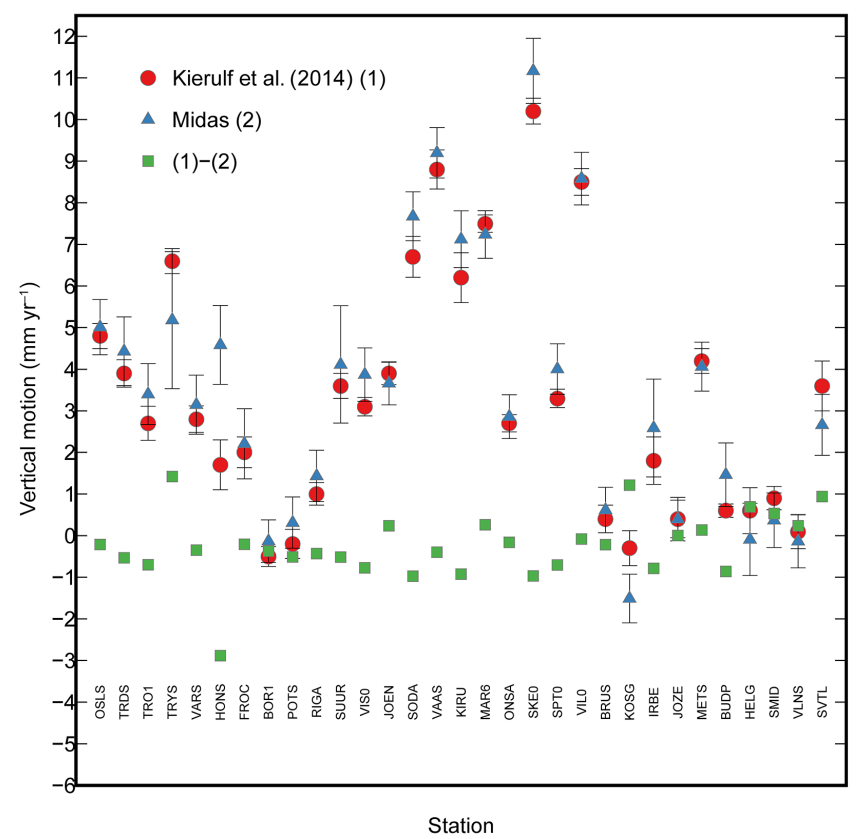

Figure A1. Vertical land motion measurements at 31 sites common to both datasets used in this study.
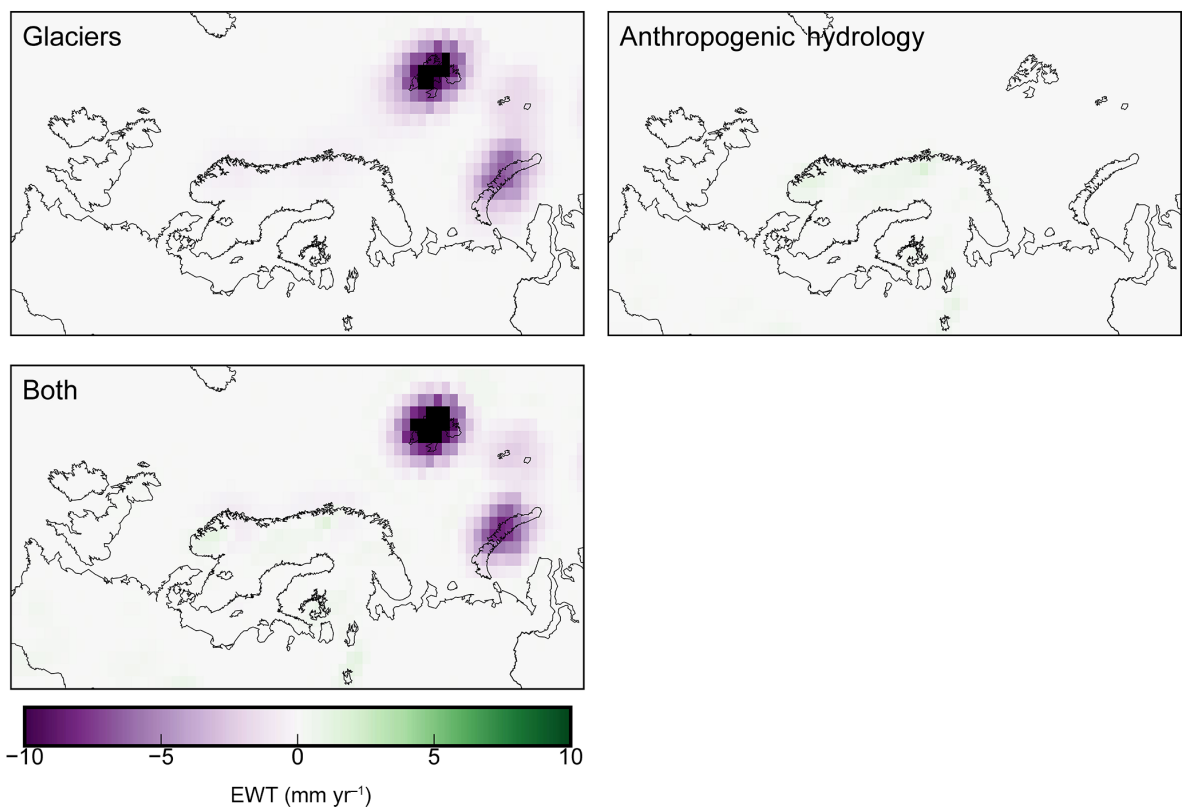

Figure A2. Individual and combined contributions to the correction applied to the GRACE data (combined is the same as Fig. 2c). 
Competing interests. The authors declare that they have no conflict of interest.

Acknowledgements. We would like to thank Anthony Purcell for providing the ANU ice sheet model for Europe and the British Isles, Yoshihide Wada for making the PCR-GLOBWB hydrology model available, and Bert Wouters for providing altimetry estimates of recent mass loss for Svalbard and the Russian Arctic. We also thank two anonymous reviewers for comments that improved the manuscript. This work is part of the project for a Multi-Scale SeaLevel model (MuSSeL), funded by the Netherlands Organization for Scientific Research, VIDI Grant No. 864.12.012.

Edited by: Simon McClusky

Reviewed by: two anonymous referees

\section{References}

Altamimi, Z., Collilieux, X., and Métivier, L.: ITRF2008: an improved solution of the international terrestrial reference frame, J. Geodesy., 85, 457-473, https://doi.org/10.1007/s00190-0110444-4, 2011

Argus, D. F., Peltier, W. R., Drummond, R., and Moore, A. W.: The Antarctica component of postglacial rebound model ICE-6G_C (VM5a) based on GPS positioning, exposure age dating of ice thicknesses, and relative sea level histories, Geophys. J. Int., 198, 537-563, https://doi.org/10.1093/gji/ggu140, 2014.

Auriac, A., Whitehouse, P. L., Bentley, M. J., Patton, H., Lloyd, J. M., and Hubbard, A.: Glacial isostatic adjustment associated with the Barents Sea ice sheet: A modelling inter-comparison, Quaternary Sci. Rev., 147, 122-135, https://doi.org/10.1016/j.quascirev.2016.02.011, 2016.

Blewitt, G., Kreemer, C., Hammond, W. C., and Gazeaux, J.: MIDAS robust trend estimator for accurate GPS station velocities without step detection, J. Geophys. Res.-Sol. Ea., 121, 20542068, https://doi.org/10.1002/2015JB012552, 2016.

Bradley, S. L., Milne, G. A., Shennan, I., and Edwards, R.: An improved glacial isostatic adjustment model for the British Isles, J. Quaternary Sci., 26, 541-552, https://doi.org/10.1002/jqs.1481, 2011.

Chao, B. F., Wu, Y. H., and Li, Y. S.: Impact of artificial reservoir water impoundment on global sea level, Science, 320, 212-214, https://doi.org/10.1126/science.1154580, 2008.

Cheng, M. K., Tapley, B. D., and Ries, J. C.: Deceleration in the Earth's oblateness, J. Geophys. Res., 118, 740-747, https://doi.org/10.1002/jgrb.50058, 2013.

Dziewonski, A. M. and Anderson, D. L.: Preliminary reference Earth model, Phys. Earth Planet. In., 25, 297-356, 1981.

Farrell, W. E.: Deformation of the Earth by surface loads, Rev. Geophys. Space Ge., 10, 761-797, 1972.

Frederikse, T., Riva, R., Kleinherenbrink, M., Wada, Y., van den Broeke, M., and Marzeion, B.: Closing the sea level budget on a regional scale: Trends and variability on the Northwestern European continental shelf, Geophys. Res. Lett., 43, 10864-10872, https://doi.org/10.1002/2016GL070750, 2016.
Gardner, A. S., Moholdt, G., Cogley, J. G., Wouters, B., Arendt, A. A., Wahr, J., Berthier, E., Hock, R., Pfeffer, W. T., Kaser, G., Ligtenberg, S. R. M., Bolch, T., Sharp, M. J., Hagen, J. O., van den Broeke, M. R., and Paul, F.: A reconciled estimate of glacier contributions to sea level rise: 2003 to 2009, Science, 340, 852-857, https://doi.org/10.1126/science.1234532, 2013.

Gunter, B. C., Didova, O., Riva, R. E. M., Ligtenberg, S. R. M., Lenaerts, J. T. M., King, M. A., van den Broeke, M. R., and Urban, T.: Empirical estimation of present-day Antarctic glacial isostatic adjustment and ice mass change, The Cryosphere, 8 , 743-760, https://doi.org/10.5194/tc-8-743-2014, 2014.

Herring, T., King, R., and McClusky, S.: Introduction to GAMIT/GLOBK release 10.4, Technical Report, Massachusetts Institute of Technology, Cambridge, USA, 2011.

Hill, E. M., Davis, J. L., Tamisiea, M. E., and Lidberg, M.: Combination of geodetic observations and models for glacial isostatic adjustment fields in Fennoscandia, J. Geophys. Res., 115, B07403, https://doi.org/10.1029/2009JB006967, 2010.

Hughes, A. L. C., Gyllencreutz, R., Lohne, Ø. S., Mangerud, J., and Svendsen, J. I.: The last Eurasian ice sheets - a chronological database and time-slice reconstruction, DATED-1, Boreas, 45, 1-45, https://doi.org/10.1111/bor.12142, 2016.

Jin, S., Zhang, T. Y., and Zou, F.: Glacial density and GIA in Alaska estimated from ICESat, GPS and GRACE measurements, J. Geophys. Res., 122, 76-90, https://doi.org/10.1002/2016JF003926, 2016.

Kierulf, H. P., Steffen, H., Simpson, M. J. R., Lidberg, M., Wu, P., and Wang, H.: A GPS velocity field for Fennoscandia and a consistent comparison to glacial isostatic adjustment models, J. Geophys. Res., 119, 6613-6629, https://doi.org/10.1002/2013JB010889, 2014.

Klees, R., Revtova, E. A., Gunter, B. C., Ditmar, P., Oudman, E., Winsemius, H. C., and Savenije, H. H. G.: The design of an optimal filter for monthly GRACE gravity models, Geophys. J. Int., 175, 417-432, https://doi.org/10.1111/j.1365246X.2008.03922.x, 2008.

Kooi, H., Johnston, P., Lambeck, K., Smither, C., Molendijk, R. Geological causes of recent $(\sim 100 \mathrm{yr})$ vertical land movement in the Netherlands, Tectonophysics, 299, 297-316, 1998.

Kuchar, J., Milne, G., Hubbard, A., Patton, H., Bradley, S., Shennan, I., and Edwards, R.: Evaluation of a numerical model of the British-Irish ice sheet using relative sea-level data: implications for the interpretation of trimline observations, J. Quaternary Sci., 27, 597-605, https://doi.org/10.1002/jqs.2552, 2012.

Lambeck, K., Smither, C., and Johnston, P.:Sea-level change, glacial rebound and mantle viscosity for northern Europe, Geophys. J. Int., 177, 102-144, 1998.

Lambeck, K., Purcell, A., Zhao, J., and Svensson, N.-O.: The Scandinavian ice sheet: from MIS 4 to the end of the last glacial maximum, Boreas, 39, 410-435, https://doi.org/10.1111/j.15023885.2010.00140.x, 2010.

Lidberg, M., Johansson, J. M., Scherneck, H.-G., and Milne, G. A.: Recent results based on continuous GPS observations of the GIA process in Fennoscandia from BIFROST, J. Geodyn., 50, 8-18, https://doi.org/10.1016/j.jog.2009.11.010, 2010. 
Marzeion, B., Jarosch, A. H., and Hofer, M.: Past and future sealevel change from the surface mass balance of glaciers, The Cryosphere, 6, 1295-1322, https://doi.org/10.5194/tc-6-12952012, 2012.

Marzeion, B., Leclercq, P. W., Cogley, J. G., and Jarosch, A. H.: Brief Communication: Global reconstructions of glacier mass change during the 20th century are consistent, The Cryosphere, 9, 2399-2404, https://doi.org/10.5194/tc-9-2399-2015, 2015.

Mémin, A., Spada, G., Boy, J.-P., Rogister, Y., and Hinderer, J.: Decadal geodetic variations in Ny-Ålesund (Svalbard): role of past and present ice-mass changes, Geophys. J. Int., 198, 285297, https://doi.org/10.1093/gji/ggu134, 2014.

Milne, G. A., Davis, J. L, Mitrovica, J. X., Scherneck, H.-G., Johansson, J. M., Vermeer, M., and Koivula, H.: Space-geodetic constraints on glacial isostatic adjustment in Fennoscandia, Science, 291, 2381-2385, 2001.

Müller, J., Naeimi, M., Gitlein, O., Timmen, L., and Denker, H.: A land uplift model in Fennoscandia combining GRACE and absolute gravimetry data, Phys. Chem. Earth, 53-54, 54-60, https://doi.org/10.1016/j.pce.2010.12.006, 2012.

Noël, B., van de Berg, W. J., van Meijgaard, E., Kuipers Munneke, P., van de Wal, R. S. W., and van den Broeke, M. R.: Evaluation of the updated regional climate model RACMO2.3: summer snowfall impact on the Greenland Ice Sheet, The Cryosphere, 9, 1831-1844, https://doi.org/10.5194/tc-9-1831-2015, 2015.

Patton, H., Hubbard, A., Andreassen, K., Auriac, A., Whitehouse, P. L., Stroeven, A. P., Shackleton, C., Winsborrow, M., Heyman, J., and Hall, A. M.: Deglaciation of the Eurasian ice sheet complex, Quaternary Sci. Rev., 169, 148-172, https://doi.org/10.1016/j.quascirev.2017.05.019, 2017.

Peltier, W. R.: Postglacial variations in the level of the sea: implications for climate dynamics and solid Earth geophysics, Rev. Geophys., 36, 603-689, 1998.

Peltier, W. R.: Global glacial isostasy and the surface of the ice-age Earth: The ICE-5G (VM2) model and GRACE, Annu. Rev. Earth Pl. Sc., 32, 111-149, https://doi.org/10.1146/annurev.earth.32.082503.144359, 2004.

Peltier, W. R. and Andrews, J. T.: Glacial-isostatic adjustment I The forward problem, Geophys. J. Roy. Astr. S., 46, 605-646, 1976.

Peltier, W. R., Argus, D. F., and Drummond, R.: Space geodesy constrains ice age terminal deglaciation: The global ICE6G_C (VM5a) model, J. Geophys. Res., 119, 450-487, https://doi.org/10.1002/2014JB011176, 2015.

Riva, R. E. M., Gunter, B. C., Urban, T. J., Vermeersen, B. L. A., Lindenbergh, R. C., Helsen, M. M., Bamber, J. L., van de Wal, R. S. W., van den Broeke, M. R., and Schutz, B. E.: Glacial isostatic adjustment over Antarctica from combined ICESat and GRACE satellite data, Earth Planet. Sc. Lett., 288, 516-523, https://doi.org/10.1016/j.epsl.2009.10.013, 2009.

Riva, R. E. M., Frederikse, T., King, M. A., Marzeion, B., and van den Broeke, M. R.: Brief communication: The global signature of post-1900 land ice wastage on vertical land motion, The Cryosphere, 11, 1327-1332, https://doi.org/10.5194/tc-11-13272017, 2017.

Root, B. C., Tarasov, L., and van der Wal, W.: GRACE gravity observations constrain Weichselian ice thickness in the Barents Sea, Geophys. Res. Lett., 42, 3313-3320, https://doi.org/10.1002/2015GL063769, 2015.
Sasgen, I., Klemann, V., and Martinec, Z.: Towards the inversion of GRACE gravity fields for present-day ice-mass changes and glacial-isostatic adjustment in North America and Greenland, J. Geodyn., 59, 49-63, https://doi.org/10.1016/j.jog.2012.03.004, 2012.

Schmidt, P., Lund, B., Näslund, J.-O., and Fastook, J.: Comparing a thermo-mechanical Weichselian Ice Sheet reconstruction to reconstructions based on the sea level equation: aspects of ice configurations and glacial isostatic adjustment, Solid Earth, 5, 371388, https://doi.org/10.5194/se-5-371-2014, 2014.

Schrama, E. J. O., Wouters, B., and Rietbroek, R.: A mascon approach to assess ice sheet and glacier mass balances and their uncertainties from GRACE data, J. Geophys. Res., 119, 60486066, https://doi.org/10.1002/2013JB010923, 2014.

Shepherd, A., Ivins, E. R., A, G., et al.: A reconciled estimate of ice-sheet mass balance, Science, 338, 1183-1189, https://doi.org/10.1126/science.1228102, 2012.

Siemes, C., Ditmar, P., Riva, R. E. M., Slobbe, D. C., Liu, X. L., and Hashemi Farahani, H.: Estimation of mass change trends in the Earth's system on the basis of GRACE satellite data, with application to Greenland, J. Geodesy., 87, 69-87, https://doi.org/10.1007/s00190-012-0580-5, 2013.

Simon, K. M., James, T. S., and Dyke, A. S.: A new glacial isostatic adjustment model of the Innuitian Ice Sheet, Arctic Canada, Quaternary Sci. Rev., 119, 11-21, https://doi.org/10.1016/j.quascirev.2015.04.007, 2015.

Simon, K. M., James, T. S., Henton, J. A., and Dyke, A. S.: A glacial isostatic adjustment model for the central and northern Laurentide Ice Sheet based on relative sea-level and GPS measurements, Geophys. J. Int., 205, 1618-1636, https://doi.org/10.1093/gji/ggw103, 2016.

Simon, K. M., Riva, R. E. M., Kleinherenbrink, M., and Tangdamrongsub, N.: A data-driven model for constraint of present-day glacial isostatic adjustment in North America, Earth Planet. Sc. Lett., 474, 322-333, https://doi.org/10.1016/j.epsl.2017.06.046, 2017.

Simon, K. M., Riva, R. E. M., Kleinherenbrink, M., and Frederikse, T.: The glacial isostatic adjustment signal at present-day in northern Europe and the British Isles estimated from geodetic observations and geophysical models, TU Delft, Dataset, https://doi.org/10.4121/uuid:4a495bbc-0478483a-baef-19ff34103dd2, 2018.

Steffen, H. and Wu, P.: Glacial isostatic adjustment in Fennoscandia - a review of data and modeling, J. Geodyn., 52, 169-204, https://doi.org/10.1016/j.jog.2011.03.002, 2011.

Steffen, H., Wu, P., and Wang, H.: Determination of the Earth's structure in Fennoscandia from GRACE and implications for the optimal post-processing of GRACE data, Geophys. J. Int., 182, 1295-1310, https://doi.org/10.1111/j.1365-246X.2010.04718.x, 2010.

Tamisiea, M. E.: Ongoing glacial isostatic contributions to observations of sea level change, Geophys. J. Int., 186, 1036-1044, https://doi.org/10.1111/j.1365-246X.2011.05116.x, 2011.

van den Broeke, M. R., Enderlin, E. M., Howat, I. M., Kuipers Munneke, P., Noël, B. P. Y., van de Berg, W. J., van Meijgaard, E., and Wouters, B.: On the recent contribution of the Greenland ice sheet to sea level change, The Cryosphere, 10, 1933-1946, https://doi.org/10.5194/tc-10-1933-2016, 2016. 
Vestøl, O., Ågren, J., Steffen, H., Kierulf, H., Lidberg, M., Oja, T., Rüdja, A., Kall, T., Saaranen, V., Engsager, K., Jepsen, C., Liepins, I., Paršeliūnas, E., and Tarasov, L.: NKG2016LU, an improved postglacial land uplift model over the NordicBaltic region, Nordic Geodetic Commission (NKG) Working Group of Geoid and Height Systems, available at: http: //www.lantmateriet.se/sv/Kartor-och-geografisk-information/ GPS-och-geodetisk-matning/Referenssystem/Landhojning/ (last access: 1 June 2018), 2016.

Wada, Y., Wisser, D., and Bierkens, M. F. P.: Global modeling of withdrawal, allocation and consumptive use of surface water and groundwater resources, Earth Syst. Dynam., 5, 15-40, https://doi.org/10.5194/esd-5-15-2014, 2014. van Wessem, J. M., Ligtenberg, S. R. M., Reijmer, C. H., van de Berg, W. J., van den Broeke, M. R., Barrand, N. E., Thomas, E. R., Turner, J., Wuite, J., Scambos, T. A., and van Meijgaard, E.: The modelled surface mass balance of the Antarctic Peninsula at $5.5 \mathrm{~km}$ horizontal resolution, The Cryosphere, 10, 271-285, https://doi.org/10.5194/tc-10-271-2016, 2016.

Wu, P. and Peltier, W. R.: Viscous gravitational relaxation, Geophys. J. Roy. Astr. S., 70, 435-485, 1982.

Zhao, S., Lambeck, K., and Lidberg, M.: Lithosphere thickness and mantle viscosity inverted from GPS-derived deformation rates in Fennoscandia, Geophys. J. Int., 190, 278-292, https://doi.org/10.1111/j.1365-246X.2012.05454.x, 2012. 